\title{
Article
}

\section{Paranormal belief, thinking style preference and susceptibility to confirmatory conjunction errors}

Rogers, Paul, Fisk, John and Lowrie, Emma Louise

Available at http://clok.uclan.ac.uk/24150/

Rogers, Paul, Fisk, John ORCID: 0000-0002-2981-0870 and Lowrie, Emma Louise (2018) Paranormal belief, thinking style preference and susceptibility to confirmatory conjunction errors. Consciousness and Cognition, 65 . pp. 182-196. ISSN 1053-8100

It is advisable to refer to the publisher's version if you intend to cite from the work. http://dx.doi.org/10.1016/j.concog.2018.07.013

For more information about UCLan's research in this area go to http://www.uclan.ac.uk/researchgroups/ and search for <name of research Group>.

For information about Research generally at UCLan please go to http://www.uclan.ac.uk/research/

All outputs in CLoK are protected by Intellectual Property Rights law, including Copyright law. Copyright, IPR and Moral Rights for the works on this site are retained by the individual authors and/or other copyright owners. Terms and conditions for use of this material are defined in the policies page.

\section{CLoK}

Central Lancashire online Knowledge www.clok.uclan.ac.uk

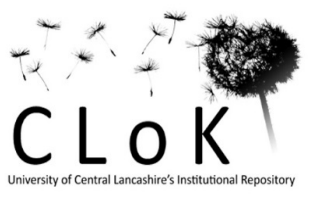


Paranormal belief, thinking style preference and susceptibility to confirmatory conjunction errors

Paul Rogers, $\mathrm{PhD}^{\mathrm{a}}$, John E. Fisk, $\mathrm{PhD}^{\mathrm{b}}$ \& Emma Lowrie ${ }^{\mathrm{b}}$

${ }^{a}$ Anomalistic Psychology Research Unit, Department of Psychology, Goldsmith's College, University of London, New Cross, London SE14 6NW UK

${ }^{\mathrm{b}}$ School of Psychology, University of Central Lancashire, Preston, Lancashire PR1 2HE, UK

Please direct correspondence to Dr Paul Rogers via progers1966@gmail.com 


\title{
Paranormal belief, thinking style preference and susceptibility to confirmatory conjunction errors
}

\section{Highlights}

1. stronger ESP, PK and afterlife believers made more conjunction errors (CEs)

2. believers also made more confirmatory (verses disconfirmatory) CEs

3. Individuals with low (versus high) NFC made marginally more confirmatory CEs

4. intuitive-experiential thinking had no impact on CE rates

5. findings are consistent with Tentori's (2013) Confirmation-Theoretical Framework

\begin{abstract}
This study examines the extent to which belief in extrasensory perception (ESP), psychokinesis (PK) or life after death (LAD), plus need for cognition (NFC) and faith in intuition $(\mathrm{FI})$, predict the generation of confirmatory conjunction errors. An opportunity sample $(n=261)$ completed sixteen conjunction problems manipulated across a 2 event type (paranormal vs. non-paranormal) $\times 2$ outcome type (confirmatory vs. disconfirmatory) within subjects design. Three Generalised Linear Mixed Models - one per paranormal belief type - were performed. With respondent gender and age controlled for, ESP, PK and LAD beliefs were all associated with the making (vs. nonmaking) of conjunction errors both generally and specifically for confirmatory conjunctive outcomes. Event type had no impact. Individuals high in NFC were less likely to commit the fallacy. The role thinking style plays in shaping paranormal believers' susceptibility to confirmatory conjunction biases is discussed. Methodological issues and future research ideas are also considered.
\end{abstract}


Keywords: PARANORMAL BELIEF; CONFIRMATION; CONJUNCTION; THINKING STYLE; PROBABILISTIC REASONING; DUAL PROCESS

\section{Introduction}

Belief in non-theistic paranormal phenomena has been linked to various cognitive “deficits" including errors of probabilistic reasoning (Rogers, 2015; Wiseman \& Watt, 2006; see also French \& Stone, 2014; Irwin, 2009). One such error is the conjunction fallacy - the tendency to misjudge two independent yet co-occurring ('conjunctive') events as being more likely than either constituent event alone (Tversky \& Kahneman, 1983) ${ }^{1}$ - with several studies

\footnotetext{
${ }^{1}$ In their original "Linda problem" Tversky and Kahneman (1983) describe the fictitious Linda as being "31 years old, single, outspoken, and very bright, who majored in philosophy and who, as a student, had been deeply concerned with issues of discrimination and social justice and who had participated in antinuclear demonstrations". Participants were asked to rank the likelihood of eight eventualities including that "Linda is an
} 
suggesting paranormal believers make more conjunction errors (CEs) than non-believers (Brotherton \& French, 2014; Dagnall, Drinkwater, Denovan, Parker \& Rowley, 2016; Prike, Arnold \& Williamson, 2017; Rogers, Davis, \& Fisk, 2009; Rogers, Fisk \& Wiltshire, 2011; Rogers, Fisk \& Lowrie, 2016; 2017). However, significant paranormal belief $\times$ CE associations have not always been found (Dagnall, Denovan, Drinkwater, Parker, \& Clough, 2016; Dagnall, Drinkwater, Parker \& Rowley, 2014; Dagnall, Parker \& Munley, 2007) with some researchers claiming this is explained by believers' broader tendency to misperceive randomness as measured by their judgment of, say, coin toss sequences (e.g. which of HHHHHH, HHHTTT or HTHHTT is most likely to occur) (e.g., Dagnall et al., 2014; 2017). Other researchers claim individual differences in believers' preference for intuitiveexperiential over rational-analytic thinking offers at least a partial explanation for their heightened CE proneness (e.g., Prike et al., 2017). Another factor that seems relevant to believers' fallacy proneness is whether the second constituent confirms or disconfirms the first (Rogers, Fisk \& Lowrie, 2016). Relevant studies are now discussed.

\subsection{Paranormal Belief \& Confirmatory Conjunction Errors}

In the aforementioned study, Rogers et al. (2016) examined the extent to which believers' tendency to make CEs differed for confirmatory over disconfirmatory conjunctions, reasoning that because believers often present strong pro-paranormal confirmation biases (e.g., Russell \& Jones, 1980; Wiseman, Greening \& Smith, 2003), they would make more errors for paranormal confirming (belief-congruent) over paranormal disconfirming (belief-

active feminist", that "Linda is a bank teller" and that "Linda is a bank teller and an active feminist (italics added). The first two statements serve as constituent events with the latter the conjunctive term. Accordingly, a conjunction error is made whenever the conjunctive term is judged more likely than one or both constituent(s) alone. Tversky and Kahneman found over $80 \%$ of participants succumbed to the fallacy despite this being normatively impossible. Subsequent research confirms this is a robust effect (see Fisk, 2017). 
incongruent) as well as non-paranormal (belief-neutral) conjunctions ${ }^{2}$. Sceptics, in contrast, would reject the paranormal premise and be less prone to paranormal confirming conjunctive biases. This argument drew on Tentori's Confirmation-Theoretical Framework (CTF; Tentori, Crupi, \& Russo, 2013) whereby CE generation is said to be shaped, not by constituent probability estimates (i.e. subjective judgements of each event's individual likelihood) as originally proposed by Tversky and Kahneman (1983), but instead by the degree to which background information increases the perceived credibility (i.e. "inductively confirms") the second constituent. Several possibilities exist. If believers and non-believers perceive background evidence as being equally credible, they will be equally prone to making CEs for non-paranormal events regardless of outcome type ${ }^{3}$. Alternatively, if believers perceive background evidence as being more credible in general they will make more CEs for confirmatory over disconfirmatory CEs (relative to non-believers) regardless of event type. Findings from Rogers et al., (2009; 2011) suggest this is the case. Finally, if believers perceive background evidence as being more credible in relation to paranormal events only, they will make more CEs for paranormal confirming over paranormal disconfirming conjunctions.

To formally test these ideas, Rogers and colleagues (2016) modified paranormal and nonparanormal conjunctive scenarios originally employed in Rogers et al. (2011) such that now, the second constituent either confirmed or disconfirmed the first. For example, background evidence in the paranormal [non-paranormal] version of Rogers et al.'s (2016) revised "motorway" scenario read as follows:

Erica is a 37 year old businesswoman who lives near Manchester. In her spare time Erica attends psychic awareness [car maintenance] classes where she is currently learning how to use precognition to 'see into the

\footnotetext{
${ }^{2}$ In the present context, belief neutral conjunctions are those that have no obvious relevance to ostensibly paranormal phenomena. By comparison, belief incongruent conjunctions are those that actively disconfirm the veracity of alleged paranormal events.

${ }^{3}$ By definition, non-believers should dismiss the credibility of any background evidence suggestive of a genuine paranormal event.
} 
future' [keep her car 'safe and roadworthy']. Erica has arranged to meet a new client in London some 250 miles away.

Respondents were then asked to rate the probability ("chances in 100") that each of three statements - the two constituent events plus their conjunction - would occur. Here, the first constituent event [statement (a)] was identical in all four (2 event type $\mathrm{x} 2$ outcome type) experimental conditions. The second constituent [statement (b)] - and by extension, the conjunctive term [statement (c)] - was manipulated to reflect one of two outcome types, such that it either confirmed or disconfirmed the first constituent event. For example, respondents who read the confirmatory version of the (revised) motorway case were asked to rate the likelihood that:

(a) Erica feels uneasy driving her car for such a long distance.

(b) Whilst on the motorway, Erica's car breaks down.

(c) Erica feels uneasy driving her car for such a long distance and whilst on the motorway, Erica's car breaks down.

Here, the first constituent describing Erica's sense of uneasiness is confirmed by the second which depicts her car as breaking down on the motorway. Respondents who read the disconfirmatory version were instead asked to rate these three statements:

(a) Erica feels uneasy driving her car for such a long distance.

(b) Whilst on the motorway, Erica's car works perfectly.

(c) Erica feels uneasy driving her car for such a long distance and whilst on the motorway, Erica's car works perfectly

Here, the first constituent describing Erica's sense of uneasiness is disconfirmed by the second which depicts her car as working perfectly and thus not breaking down. In all cases, a conjunction error was made whenever the conjunctive term [statement (c)] was deemed more likely than either or both the constituent event(s) alone (cf. Tversky \& Kahneman, 1983).

Rogers and colleagues (2016) found stronger paranormal believers made more CEs than weaker believers, with this the case regardless of whether events depicted an ostensibly 
paranormal or a clearly non-paranormal event. This suggests stronger paranormal believers are more prone to context free conjunctive biases further supporting the generality of their fallacy proneness (Rogers et al., 2009; 2011).

As hypothesised, stronger believers also made more CEs when the second constituent confirmed rather than disconfirmed the first, implying they were also more prone to a confirmatory conjunction fallacy. In contrast, believers' propensity for confirmatory CEs did not differ across outcome type with believers making as many CEs for paranormal confirming as they did paranormal disconfirming conjunctions. In short, believers' heightened fallacy proneness was not limited to pro-paranormal (belief congruent) conjunctions.

Finally, trends were noticeably stronger for individuals with a more pronounced belief in extrasensory perception (ESP: $b=.18 ; p=.001)$ and psychokinesis $(\mathrm{PK}: b=.19 ; p<.001)$ relative to those endorsing the veracity of life after death (LAD: $b=.14 ; p=.069$ ), with the latter only approaching significance ${ }^{4}$. This seems reasonable given conceptual differences in these constructs (Irwin \& Watt, 2007) together with previous evidence that whilst ESP and PK endorsement is associated with flawed probabilistic reasoning LAD endorsement is more reflective of socio-cultural, religious, philosophical and/or motivational factors such as the need to believe in an afterlife (Rogers, 2015; Thalbourne, 1996).

To summarize: findings from Rogers et al (2016) suggest individuals with a more pronounced paranormal belief - particularly in ESP and PK - are especially susceptible to a generic (context-free) and confirmatory - rather than just paranormal confirming -

\footnotetext{
${ }^{4}$ ESP is defined as the alleged ability to obtain information directly via means other than the known senses or logical inference. PK is the alleged ability to influence physical systems (e.g., objects, biological organisms) directly through mental processes. Finally, LAD reflects the notion that some disembodied aspect of human personality or consciousness survives bodily death. Often, the term "psi" - pronounced "sigh" - is used to denote the unknown paranormal element thought to underlie both ESP and PK (Irwin \& Watt, 2007). It should be noted that Rogers et al. (2016) failed to report $\exp (b)$ coefficients for any predictor and additionally, did not perform analyses to directly compare $b$ coefficients across the three paranormal belief types. As such, the extent to which ESP and PK beliefs are significantly stronger predictors of CE rates than LAD beliefs remains speculative.
} 
conjunction fallacy. That said, CE rates across different types of paranormal belief have been inconsistent with Rogers et al.'s (2017) finding that only PK believers were especially prone to conjunctive biases. Given mixed findings, one aim of the current study is to re-examine the extent to which ESP, PK and LAD endorsement uniquely predict the generation of CEs, in particular confirmatory conjunction errors (Rogers et al., 2016). A second aim is to test the robustness of believers' propensity for conjunction biases - overall as well as specifically for confirmatory conjunctions - once individual differences in thinking style preference have been controlled for. The relevant thinking styles literature is now discussed.

\subsection{Thinking Style Preference}

According to dual processing theory judgments are made via two independent yet interacting information processing systems; intuitive-experiential or System 1 thinking which is spontaneous, effortless preconscious, holistic and emotion-orientated reflecting what feels right, plus analytic-rational or System 2 thinking, which is deliberate, effortful, conscious, specific and reason-orientated reflecting what is thought to be right (e.g., Epstein, 2013; Kahneman, 2011). Whilst both contribute to decision making, default responses tend to be heuristical and thus on the former unless subsequently over-ridden by the latter (Evans \& Stanovich, 2013).

As already implied, paranormal believers' heightened CE proneness may be at least partially explained by individual differences in preferred thinking style (e.g., Prike et al., 2017). First, numerous studies have linked adult paranormality to a heightened preference for intuitive-experiential thinking and/or a diminished preference for analytic-rational or reflective thinking (e.g., Bouvet \& Bonnefo, 2015; Irwin, 2015; Irwin \& Wilson, 2013; Lobato, Mendoza, Sims \& Chin, 2014; Pennycook et al., 2015; Pennycook, Cheyne, Seli, Koehler, \& Fugelsang, 2012; Prike et al., 2017; see also French \& Stone, 2014; Irwin, 2009). For instance, in their Belief-Unbelief Asymmetry model, Pennycook and colleagues (2012) 
argue that endorsement of paranormal (and religious) concepts is a default psychological state driven by evolutionarily adaptive heuristical processes. Consequently, individuals predisposed to a more analytic style of thinking are less likely to endorse paranormal concepts not because they are less intuitive per se but instead because they are more inclined to scrutinize then override ("un-believe") any pro-paranormal intuitions they have.

Individuals predisposed to a more intuitive thinking style tend to engage less, if at all, in such scrutiny.

However, the relationship between preferred thinking style and adult paranormality has not always been straightforward with a number of studies finding higher levels of both analytic-rational and intuitive-experiential thinking were associated with a more pronounced paranormal worldview (e.g., Majima, 2015; Wolfradt, Oubaid, Straube, Bischoff \& Mischo, 1999) with others finding no thinking style $\times$ paranormal belief association (e.g., Gray \& Gallo, 2016). Nevertheless, most work suggests adoption of intuitive-experiential (System 1) thinking is a significant factor in shaping adults' paranormal worldview (French \& Stone, 2014).

Second, individual differences in the propensity to override intuitive with reflective thinking exist (e.g., De Neys \& Bonnefon, 2013; Stanovich \& West, 2000), with a tendency to rely on the former shown to underlie many, if not all, probabilistic reasoning biases (Phillips, Fletcher, Marks and Hine, 2016) including the conjunction fallacy (Epstein, DenesRaj \& Pacini, 1995; Toyosawa \& Karasawa, 2004).

Recent work has also linked thinking style preference to errors in probabilistic reasoning as a potential explanation for paranormal endorsement. Bouvet and Bonnefon (2015) found intuitive thinkers were less likely to offer statistical explanations for the apparent accuracy of a fake personal horoscope (Study 1) and a mock ESP demonstration (Study 2), with intuitive thinkers more inclined to accept a paranormal explanation of the latter. Similarly, Pennycook 
et al. (2015) found paranormal belief correlated positively with faith in intuition (FI) and negatively with reflective thinking, with the latter measured via aggregate scores on a battery of 15 classic heuristics and biases tasks first assembled by Toplak, West and Stanovich, (2011) $)^{5}$. Unfortunately, Pennycook and colleagues did not report correlations between paranormal belief and CE scores alone. Finally, Prike et al (2017) separated personal experience of anomalous phenomena from a belief in the theoretical possibility of ESP, PK and LAD, as well as extraterrestrial visitation, being real. Whilst all four belief scales correlated positively with the number of CEs made, regression analysis revealed more anomalous experiences alone predicted higher CE rates. According to these authors, a heightened tendency to rely on intuitive-experiential thinking is most likely to explain believers' tendency to attribute paranormal causes to otherwise inexplicable personal experiences such seemingly remarkable coincidences (co-occurrences). A theoretical belief in paranormal phenomena, by contrast, is more likely to reflect a reasoned analysis of, say, the academic parapsychological literature and/or the philosophical plausibility of such concepts being real. Such theoretical beliefs are less likely to shape conjunctive biases (Prike et al., 2017).

\subsection{Study Overview \& Hypotheses}

Taking an individual differences perspective, the current study attempts to replicate and built upon previous work by examining the extent to which stronger paranormal beliefs predict the making of conjunction errors for paranormal (versus non-paranormal) events and/or confirmatory (versus disconfirmatory) outcomes. In this way, the extent to which believers are especially prone to belief-congruent over belief-neutral CEs is again tested with, as before, belief in three types of alleged paranormal phenomena - ESP, PK and LAD -

\footnotetext{
5 Toplak et al.'s (2011) battery included Tversky and Kahneman's original "Linda problem" (see Footnote 1) as well as causal base-rate, sample size, regression to the mean, gambler's fallacy, covariation detection, methodological reasoning, Bayesian reasoning, framing, denominator neglect, probability matching, sunk cost and outcome bias tasks. All tend to illicit incorrect, heuristically-driven responses.
} 
assessed separately (cf. Rogers et al., 2016). In an extension to previous work, the role intuitive-experiential and rational-analytic thinking play in this process is also explored. As such, the present study is the first to test the impact paranormal belief type and strength has on both general and confirmatory CE generation controlling for individual differences in thinking style plus relevant demographics.

Several hypotheses are advanced. First, with relevant demographics controlled for, individuals with stronger paranormal beliefs (all types) will make more CE's generally [H01], more CEs for paranormal over non-paranormal events [H02], more CEs for confirmatory over disconfirmatory outcomes [H03] and more CEs for confirmatory paranormal over all other conjunction types [H04] than those with less pronounced paranormal beliefs. Second, parallel main and interaction effects are anticipated for individuals reporting a lower need for cognition [H05, H06, H07 and H08 respectively] and a higher faith in (their own) intuition [H09, H10, H11 and H12 respectively]. Relative to previous work the strength of paranormal belief (all types) as a predictor of CE rates should be diminished once baseline differences in analytic-rational and intuitive-experiential thinking style have been partialled out [H13 and H14 respectively]. Finally, trends involving paranormal belief will be more pronounced for individuals endorsing ESP and PK over LAD [H15 and H16 respectively]. Given their conceptual similarity, no differences between ESP and PK beliefs are anticipated.

\section{Method}

\subsection{Participants}

An opportunity sample was recruited from various locations in the North-West and South Coast regions of England ( $n=262$; overall response rate=81.9\%). Respondents were aged from 16 to 84 years ( $M=37.1$ years; $S D=16.5$ years) with most being female (54.0\%), of Caucasian ethnicity (93.2\%) and either employed (63.2\%), retired (10.8\%) or in post- 
compulsory education $(12.8 \%)$. Around two-fifths of the sample were educated to undergraduate degree level or better (44.8\%) with a sizeable proportion qualified to this level in maths, statistics and/or psychology (16.5\%). No other demographics details were taken.

\subsection{Design}

The study employed a 2 (event type: paranormal versus non-paranormal) x 2 (outcome type: confirmatory versus disconfirmatory) within subjects design with the presence (versus absence) of a conjunction error for each scenario serving as the dependent measure. As with previous studies (Rogers et al., 2016; 2017), CE generation was assessed via Generalised Linear Mixed Modelling (GLMM) with the aforementioned experimental factors, together with paranormal belief, two thinking styles (NFC and FI) plus relevant interaction terms entered as potential predictors, and demographic correlates entered as potential covariates. As before three GLMMs - each incorporating a single paranormal belief type (ESP, PK or LAD) - were performed.

\subsection{Materials}

A pack comprising a brief/instruction sheet, the four questionnaires describe below and a detachable debrief sheet was created, with a reversed version also fashioned to overcome possible order effects.

\subsubsection{Scenario Judgements Questionnaire (SJQ)}

Taken from Rogers et al. (2016), the SJQ contains 16 hypothetical scenarios covering a range of topics, with formatting the same as that in the "motorway" case illustrated above. To reiterate, each scenario comprised background information followed by three statements; two constituent events [statements (a) and (b)] plus their conjunction [statement (c)]. Background evidence depicted one of two event types; either an ostensibly paranormal experience (e.g., apparent precognition seemingly derived from taking psychic awareness classes) else a clearly non-paranormal occurrence (e.g., knowledge about car safety and roadworthiness 
acquired from taking car maintenance classes). The first constituent was identical in all four (2 event type x 2 outcome type) experimental conditions. The second constituent was manipulated across two outcome types, such that the first constituent (e.g., "Erica feels uneasy driving her car for such a long distance") was either inductively confirmed (i.e. "Whilst on the motorway, Erica's car breaks down.") else inductively disconfirmed (i.e. "Whilst on the motorway, Erica's car works perfectly"). As before, the conjunction term comprised the two constituent statements connected by the term "and". A conjunction error was made whenever the conjunctive term was deemed more likely than either or both constituents alone; that is, whenever statement (c) was given a higher subjective probability score than statement (a) and/or statement (b). A worked example was included in SJQ instructions.

\subsubsection{Belief in the Paranormal}

Paranormal belief was assessed using the Australian Sheep-Goat Scale (ASGS: Thalbourne \& Delin, 1993) a psychometrically sound, 18 item measure of peoples' belief in ESP, PK and LAD (Thalbourne, 2010). Items are rated along a 7-point Likert scale from 1 'strongly disagree' to 7 'strongly agree' with higher ASGS scores reflecting a stronger endorsement of each paranormal concept.

\subsubsection{Thinking Styles}

Respondents' preferred style of thinking was assessed via the Rational-Experiential Inventory (REI; Epstein, Pacini, Denes-Raj \& Heier, 1996), a 31 item questionnaire comprising two orthogonal subscales. The first, termed Need for Cognition (NFC), reflects peoples' preference for rational-analytic thinking and complex problem solving (e.g., "I prefer my life to be filled with puzzles that I must solve"). The second, labelled Faith in Intuition (FI), reflects their endorsement of and preference for intuitive-experiential thinking (e.g., "I believe in trusting my hunches"). For current purposes, these were rated on a 7-point 
Likert scale from 1 'extremely uncharacteristic of me' to 7 'extremely characteristic of me', with higher NFC and FI scores (re)coded to reflect a stronger preference for analytic-rational and experiential-intuitive thinking respectively. According to Epstein et al. (1996) both NFC $(\alpha=.87)$ and FI $(\alpha=.77)$ subscales demonstrate acceptable levels of internal reliability. In the present study, corresponding alpha coefficients reached at least .85 (see Results section).

\subsubsection{Demographics}

A standard demographics questionnaire ascertained respondents' gender, age, ethnicity (16 categories), occupational status (12 categories) and highest qualification both (a) generally as well as (b) specifically in mathematics/statistics and/or psychology (both from 1 'none' to 5 'postgraduate/professional'). Data from a sixth category 'other' qualifications was dropped.

\subsection{Procedure}

Respondents were recruited from medium-sized businesses (e.g., corporate coffee shops) in four locations in the North-West (Preston, Blackpool, Blackburn) and South coast (Portsmouth) regions of England. With management permission, individuals were randomly approached and asked if they would like to take part in 'a study of event likelihoods'. Volunteers were given brief verbal instructions and handed a questionnaire pack to complete on site. No time limit was set with no form of payment made. Completed questionnaires were returned either to the researcher (PR or EL) in person else via the national post.

\section{Results}

\subsection{Preliminary Analyses}

A single under-age (<16 year old) respondent was omitted from the data set. Descriptive, reliability and normality data for the three paranormal belief (ASGS) and two thinking style (REI) subscales are presented in Table 1. As this shows, all measures had good internal reliability ( $\alpha$ 's $\geq .76$ ) with deletion of one NFC item and one FI item improving alpha coefficients to the levels shown. 
Descriptives revealed that two of the five subscales were significantly skewed, with PK beliefs presenting substantial positive skew $\left(I S=.68 S E_{\text {Skew }}=.15 ; Z=4.39 ; p<.001\right)$ and FI presenting similar negative skew FI $\left(I S=-.50 S E_{\text {Skew }}=.15 ; Z=3.25 ; p<.001\right)$. Histograms and Q-Q plots confirmed the non-normality of these measures, particularly PK beliefs. Subsequent examination of boxplots revealed six outliers, all for FI ratings. These were removed, with FI skew subsequently falling to the non-significant level reported in Table 1. Given their substantial positive skew but lack of outliers PK belief ratings were subjected to natural logarithmic transformation with this reducing skew to a non-significant level (IS=.05; $S E_{\text {Skew }}=.15 ; Z=.30 ; p>.05 ; n s ; M=.33 ; S D=.27 ;$ observed range from 0.00 to 0.85 ; median=.35). All future analyses incorporate log transformed PK beliefs.

$* * *$ Table 1 here $* * *$

\subsection{Probability Estimates and Conjunction Error Rates}

Some proportion of respondents made CEs for every scenario (observed range $34.5 \%$ to $53.5 \% ; M=42.0 \% ; S D=5.7$; median=42.0) rendering all suitable for inclusion in the present study. Overall, the total number of CEs made - hereafter the "CE rate" - was moderately high (observed range 0 to $15 ; M=6.63 ; S D=3.78$; median $=7.00 ; n=246$ ), not significantly skewed $\left(I S=01 ; S E_{\text {Skew }}=.16\right)$ and free of outliers, with histograms and Q-Q plots confirming CE data to be suitable for parametric analysis.

\subsection{Correlations}

Correlations between the $\mathrm{CE}$ rate (across all conditions) and the various individual difference (ASGS, REI) and demographic measures are presented in Table 2. As illustrated, the overall CE rate correlated positively with ESP, PK and LAD beliefs, faith in intuition (FI) and respondents' (female) gender plus negatively with need for cognition (NFC) ratings. Unsurprisingly, the three paranormal belief types were highly inter-correlated as were the two thinking styles. All three belief types were associated with lower NFC and higher FI. 
For the most part, the three paranormal belief types were more pronounced amongst respondents who were female, lower in age, of non-Caucasian ethnicity, a non-student and less qualified both generally and specifically in maths, statistics and/or psychology. Two exceptions were found. First, PK beliefs were unrelated to maths, statistics and/or psychology-specific qualification levels and second, LAD beliefs were not associated with respondents' Caucasian (versus non-Caucasian) ethnicity. Relationships between demographics and the two thinking styles were less clear-cut. Whilst higher NFC was associated with Caucasian ethnicity plus more general and more maths/statistics/psychologyspecific qualifications, higher FI was associated only with student (vs. non-student) occupational status and general qualification levels. With a few exceptions, the six demographic items were inter-correlated. No evidence of predictor multicollinearity was found (all $r$ 's $\leq .61$ ) with no paranormal belief $\times$ thinking style correlation exceeding $r=.35$.

\subsection{Correlations across Event $\times$ Outcome Types}

Correlations between CE rates and all individual difference measures across the four (2 event type $\times 2$ outcome type) experimental conditions are given in Table 3 . Noticeably, positive $\mathrm{CE} \times$ belief correlations were found for three of the four conditions, the exception being that PK beliefs were unrelated to CEs for paranormal disconfirmatory scenarios. Noticeably stronger $r$ coefficients were observed for (all) confirmatory relative to disconfirmatory scenarios.

*** Table 3 here $* * *$

As Table 3 also shows, negative CE $\times$ NFC correlations along with (marginally) positive $\mathrm{CE} \times$ FI correlations were observed for all conditions except paranormal disconfirmatory scenarios. Positive $\mathrm{CE} \times$ gender correlations were also (marginally) significant regardless of condition with these stronger for females then for males. Finally, negative $\mathrm{CE} \times$ age 
correlations were observed for all conditions except those for confirmatory paranormal scenarios which were negative in sign. No other consistent pattern of $\mathrm{CE} \times$ demographic correlations emerged.

\subsection{Generalised Linear Mixed Modelling}

The extent to which scenario event type, outcome type, strength of paranormal belief, thinking style (NFC and FI) preference plus relevant interaction terms predicted the presence versus absence of conjunction errors (“CE generation") were examined via Generalised Linear Mixed Modelling with, as previously noted, one GLMM conducted per paranormal belief type (ESP, PK or LAD) ${ }^{6}$. In each case respondents' gender and age were entered as potential covariates (cf. Table 2). In line with guidelines (Field, 2013; Norušis, 2007) all nondichotomous predictors were grand mean centred prior to analyses with the criteria reference point set to the non-making of CEs (i.e. to correct conjunctive judgements).

\subsubsection{Model Structure \& Fit}

Separate GLMMs assessed scaled identity then diagonal, first order auto-regression (AR1) and compound symmetry covariance structures, again one per paranormal belief type. Models with compound symmetry structures failed to converge with, in all cases, the AR1 structure producing the best model fit.

GLMMs also assessed the unique contribution each additional predictor (step) made to the overall model fit. In most steps, inclusion of the next predictor improved model fit to a significant or near-significant degree. The exceptions were inclusion of the NFC $\times$ event $\times$ outcome interaction term at Step 15 for all paranormal belief types, and inclusion of the FI $\times$

\footnotetext{
${ }^{6}$ As noted elsewhere (Rogers et al., 2016) GLMM is a more flexible extension of standard regression analysis in that it differentiates fixed from random effects. Further, GLMM is able to overcome potential limitations of missing data, non-independent observations, non-homogeneous regression slopes, non-constant error variance and for within subjects design, non-sphericity, this raising statistical power (see Field, 2013). As such, GLMM was deemed most suitable for current purposes.
} 
event $\times$ outcome interaction at Step 15 for the LAD beliefs model. Inclusion of the random (versus fixed) intercept also improved the overall fit of each model regardless of belief type. Full details of these model fit data are provided in Supplementary Tables 1 to 3.

\subsubsection{Statistical Power}

The final sample of 259 respondents (4144 cases) was comparable to previous research of on this topic (Rogers et al., 2016). Power analysis confirmed that for an omnibus logistic regression ${ }^{7}$ with 16 predictors/covariates, $\alpha$ set to .05 and statistical power $(1-\beta)$ set to .95 , an $n$ of 259 was sufficient to detect small-to-medium effect sizes $\left(f^{2}=.12\right)$.

\subsubsection{Classification Accuracy}

Table 4 shows that for the three models with a fixed intercept, respondents correctly classified around 16-20\% of conjunction errors, just under $90 \%$ of non-errors and just under $60 \%$ of all responses regardless of whether ESP, PK or LAD beliefs served as the beliefbased predictor. Inclusion of the random intercept term increased classification accuracy for errors to around $57-58 \%$, for non-errors to roughly $80 \%$ and for all responses to just over $70 \%$, again in all three belief-based models. With GLMM analyses requiring inclusion of the random intercept on conceptual grounds (Twisk, 2006), only random intercept models with an AR1 covariance structure are discussed further.

*** Table 4 here $* * *$

\subsubsection{Predictors of Conjunction Error Generation}

Table 5 presents inferential statistics for each of the three belief-based models. In each case the ARl diagonal statistic was highly significant indicating a lack of homogeneity in estimated variance-covariance residuals - hence non-consistent unexplained variance - across different level 1 variables (here, the 16 scenarios). ARl rho indicates the degree of first-order autocorrelation between residuals across the level 1 variable (scenarios) given the same

\footnotetext{
${ }^{7}$ With $G^{*}$ Power (Buchner, Erdfelder, Faul \& Lang, 1992-2008) not offering power analysis for GLMMs, an omnibus test of logistic regressions is reported as a proxy for current analyses.
} 
"contextual" variable (here, respondent id). As Table 5 shows, all three ARl rho statistics were significant implying that some unexamined factor(s) within each respondent had significant impact on CE generation (Field, 2013).

$$
* * * \text { Table } 5 \text { here } * * *
$$

As Table 5 also shows, neither respondent gender nor respondent age predicted the making (versus non-making) of CEs to a significant degree in any model. Nevertheless, subsequent findings are for when these two demographic measures are controlled for.

\subsubsection{Event and Outcome Types: Event and outcome types failed to predict CE} generation either uniquely or in combination.

3.5.4.2. Paranormal Belief: As expected, all three paranormal belief types predicted CE generation in their own right with $\exp (b)$ coefficients for ESP, PK and LAD beliefs being 1.32, 3.16 and 1.27 respectively (see Table 5). Thus, with all other predictors set at the respective means (i.e. "averaged") a unit increase in ESP beliefs heightened the odds of making (versus not making) a CE by approximately a third. A comparable unit increase in PK beliefs enhanced the odds of CE generation over threefold ${ }^{8}$ whereas a unit increase in LAD beliefs raised them by just over a quarter. In short, H01 was fully supported.

The lack of any significant belief $\times$ event interactions suggest the above trends existed regardless of whether scenarios depicted an ostensibly paranormal or a clearly nonparanormal event, meaning $\mathrm{H} 02$ is unsupported.

By comparison, three significant belief $\times$ outcome interactions (one per belief type) emerged. Relevant $\exp (b)$ coefficients indicate that with all other predictors averaged, the shift from a disconfirmatory to a confirmatory outcome (coded -1 and +1 respectively) combined with a unit increase in ESP beliefs meant the odds of making a CE increased by a ratio of .76. In other words, as ESP beliefs increased by one unit, respondents were 1/.76 or

\footnotetext{
${ }^{8}$ As already noted, PK beliefs were subjected to natural logarithmic transformation which, by definition, alters the precise relationship this belief type has on the odds of CE generation.
} 
1.32 times more likely to make a $\mathrm{CE}$ for confirmatory relative to disconfirmatory outcomes (cf. Field, 2013). By similar reasoning, as PK beliefs increased by one unit, respondents were 1/.25 or four times more likely to make a confirmatory CE relative to a disconfirmatory CE. Finally, a unit increase in LAD beliefs meant respondents were $1 / .78$ or 1.28 times more susceptible to confirmatory over disconfirmatory CE generation. Simple effects analyses with $\alpha$ adjusted to .0125 - confirmed that stronger ESP believers, $b=.27 ; t=3.80 ; p<.001$; $\exp (b)=1.31 ; \mathrm{CI}_{95}[1.14,1.51]$, stronger PK believers, $b=1.09 ; t=2.88 ; p=.004 ; \exp (b)=2.98$; $C I_{95}[1.42,6.28]$, and stronger LAD believers, $b=.22 ; t=3.39 ; p=.001 ; \exp (b)=1.25 ; C_{95}[1.10$, 1.42] were more likely to make CEs for confirmatory outcomes than were those with weaker ESP, PK and LAD beliefs respectively. This was not the case when scenario outcomes were disconfirmatory in nature (all $p$ 's $>.500 ; n s$ ). In sum, H03 is fully supported.

Finally, the absence of any significant three-way belief $\times$ event $\times$ outcome interactions suggest odds ratios for confirmatory versus disconfirmatory CEs were unaffected by whether scenarios depicted an ostensibly paranormal or a clearly non-paranormal event. Hence, H04 is unsupported.

\subsubsection{Rational-Analytic Thinking: As expected, lower NFC predicted heightened CE} generation in all three models. Specifically, with all other predictors averaged, a unit increase in NFC unit lowered the odds of making (versus not making) a CE by approximately a quarter regardless of whether ESP, PK or LAD beliefs served as the belief-based predictor. Turned around, a unit decrease in NFC raised the odds of CE generation by around a quarter irrespective of paranormal belief type. As such, H05 is supported.

The lack of any significant NFC $\times$ event interactions suggests the above trends were just as prominent for paranormal as for non-paranormal events, meaning H06 is unsupported. That said, three near-significant NFC $\times$ outcome interactions were found, having $\exp (\mathrm{b})$ 
coefficients of $1.25,1.23$ and 1.24 for the ESP, PK and LAD based models respectively ${ }^{9}$. Thus, with all other predictors averaged, the shift from a disconfirmatory to a confirmatory outcome combined with a unit increase in NFC ratings meant the odds of CE generation increased by (roughly) a quarter. Given that all three NFC $\times$ outcome interactions are marginally significant, H07 can be accepted with caution. The absence of any significant three-way interactions involving NFC means the aforementioned trend does not differ across paranormal versus non-paranormal event types. Thus, H08 remains fully unsupported.

3.5.4.4. Intuitive-Experiential Thinking: For the most part FI scores had little impact on CE generation. The sole exception was the near-significant main effect FI had within the PKbased model where a unit increase in FI raised the likelihood of CE generation by a quarter. At first glance, this marginal effect appears to offer partial support for H09. However, because it occurs only within the PK-based model, with such beliefs subjected to a logarithmic transformation, overall evidence points to H09 being unsupported. The absence of any significant two or three-way interactions involving FI means H10, H11 and H12 are unsupported too.

3.5.4.5. Paranormal Belief Net of Thinking Style. Rogers et al. (2016), who did not control for baseline differences in thinking style preference, report $b$ coefficients for ESP, PK and LAD beliefs (as predictors of CEs generally) to be $.18, .19$ and .14 respectively ${ }^{10}$. In the current study, corresponding $b$ coefficients were $.28,1.15$ and .24 respectively. Thus, with NFC and FI both controlled for, the predictive strength of ESP, PK and LAD beliefs increased, contrary to hypotheses. Whilst a direct cross-study comparison for PK beliefs is not possible due to their logarithmic transformation in the present work overall directional trends point to both $\mathrm{H} 13$ and $\mathrm{H} 14$ being unsupported.

\footnotetext{
${ }^{9}$ The similarity in $\exp (b)$ coefficients for (a) NFC and (b) NFC $\times$ outcome interactions is unsurprisingly given that these predictors do not incorporate a paranormal belief type element.

${ }^{10}$ Rogers et al. (2016) did not report $\exp (b)$ coefficients.
} 
3.5.4.6. Comparison of Paranormal Belief Types: In the current study, significant main and interaction effects involving ESP and LAD beliefs were virtually identical with, by comparison, those involving PK beliefs noticeably stronger. However, with PK beliefs subjected to natural logarithmic transformation direct comparison of (the strength of) these relationships cannot be made (Field, 2013). As such, H15 remains unsupported whilst support for H16 cannot at present be determined.

\section{Discussion}

The three GLMMs with AR1 covariance structures all predicted the presence (vs. absence) of conjunction errors to a significant degree, indicating all scenarios were suitable for current purposes. Several hypotheses were supported.

First, stronger paranormal belief was associated with more CEs supporting previous claims that believers are especially prone to the conjunction fallacy (Brotherton \& French, 2014; Dagnall, Denoven et al., 2016; Prike et al., 2017; Rogers et al., 2009; 2011, 2016; 2017) and by implication, to probabilistic reasoning biases (Rogers, 2015) and certain cognitive "deficits" (French \& Stone, 2014; Irwin, 2009). Such findings contrast with those of Dagnall and colleagues $(2007 ; 2014 ; 2016)$ who found no relationship between paranormal belief and fallacy proneness.

Second, believers' made as many CEs regardless of whether background evidence depicted an ostensibly paranormal versus clearly non-paranormal event. This replicates previous claims that believers' fallacy proneness is not exclusive to ostensibly paranormal events (Brotherton \& French, 2014; Rogers et al., 2009; 2011, 2016). It would seem believers' proneness to a generic or context-free conjunction fallacy is now well established. By extension, potential differences in the objective odds of paranormal versus non-paranormal co-occurrences (“scenario asymmetry") had no impact on respondents' proneness to conjunctive biases with background evidence just as inductively confirming (cf. Tentori et 
al., 2013) irrespective of whether it depicted an ostensibly paranormal or a clearly nonparanormal event.

Third, whilst outcome type had no main impact on CE rates three highly significant belief $\times$ outcome interactions were found. The implication here is that stronger paranormal believers demonstrated more extreme confirmatory conjunction biases than those relatively sceptical of paranormal claims. Whilst current findings are contrary to the pro-paranormal confirmation biases found for other cognitive (e.g., learning and memory) tasks (Russell \& Jones, 1980; Wiseman et al., 2003), they do support previous claims that paranormal believers are especially susceptible to a generic (context-free) and confirmatory conjunction fallacy (Rogers et al., 2016) with inductive confirmation, for some unknown reason, more applicable to paranormal believers irrespective of event type. One possibility is that believers simply require less evidence of inductive confirmation because they are less inclined towards critical reasoning (French \& Stone, 2014; Irwin, 2009), this time in relation to conjunctive probability estimations. Such argument is consistent with the notion that paranormal believers and sceptics have a different internal representation of what constitutes a random event, with believers requiring less subjective evidence of relatedness before they start to see meaningful patterns in what is essentially meaningless data (e.g. Hadlackzy \& Westerfield, 2011; see Rogers, 2015).

In the current study, all three paranormal belief types were strongly associated with confirmatory CEs. Noticeably, the predictive strength of ESP beliefs was virtually identical to that of LAD beliefs ${ }^{11}$. From this it would seem that some underlying dimension - presumably a "global" tendency to endorse all paranormal claims relating to ESP, PK and LAD accounts for believers' heightened proneness to confirmatory conjunction biases. Thus, current trends are consistent with Rogers et al. (2106) who report greater fallacy proneness in relation ESP,

\footnotetext{
${ }^{11}$ Again, direct comparison with logarithmically transformed PK beliefs should not be made.
} 
PK and to a lesser (marginal) extent LAD endorsement. Thus, previous work by Rogers and colleagues (2016) has, for the most part, been replicated and extended more robustly to individuals accepting the veracity of life after death.

\subsection{Thinking Style Preference}

Consistent with a host of previous studies (e.g., Irwin, 2015; Lobato et al., 2014), paranormal believers demonstrated a lower preference for rational-analytic thinking as well as a stronger preference for intuitive-experiential thinking. As hypothesised, lower rationalanalytic thinking predicted more CEs generally whereas, contrary to hypotheses, intuitiveexperiential thinking was, on the whole, unrelated to overall CE rates. Only in the PK model did stronger intuitive preference even approach significance as a CE predictor $(p=.057)$ with this most likely a statistical artefact. Together, current suggest susceptibility to the conjunction fallacy reflects a tendency to avoid analytic-rational thinking rather than to knowingly rely on one's intuitions. One possibility is that rationality-avoidant individuals do not over-ride their automatic (heuristical) processing with a more reflective consideration of conjunctive problems, thereby highlighting potential limitations in their own metacognitive awareness (cf. De Neys \& Bonnefon, 2013; Pennycook et al., 2012).

Neither NFC nor FI predicted CE generation for paranormal over non-paranormal events, contradicting previous evidence linking preference for intuitive-experiential thinking to a proparanormal interpretation of anomalous experiences (cf. Bouvet \& Bonnefon, 2015; Prike et al., 2015). By comparison, NFC $\times$ outcome interactions were marginally predictive of CEs in all three belief-based models ( $p$ values from .058 to .076), with individuals who prefer to avoid analytic-rational thinking making marginally more confirmatory CEs than (a) they did for disconfirmatory CEs and (b) relative to individuals who prefer to engage in analyticrational thinking. By comparison, preference for intuitive-experiential thinking was unrelated to both confirmatory and disconfirmatory $\mathrm{CE}$ rates. It is possible rationality-avoidant 
individuals stopped trying to solve confirmatory conjunction tasks using reasoned analysis because they found these - but for some reason not disconfirmatory tasks - too challenging. Future studies should consider assessing the perceived difficulty of conjunction problems directly.

\subsection{Follow-Up Analyses}

Controlling for individual differences in both NFC and FI appeared to raise the predictive strength of ESP, PK and LAD beliefs. The implication here is that individual differences in preferred thinking style acts as a CE buffer in relation to all three types of paranormal endorsement (Rogers et al., 2016). However, as one anonymous reviewer suggested, it is still possible baseline differences in rational and/or intuitive thinking style account for why paranormal believers make more conjunction errors. To explore this claim further, follow-up GLMMs were performed this time with paranormal belief, low versus high NFC, low versus high FI, outcome type and all relevant interaction terms entered as potential predictors. With main analyses revealing no main or interaction effects involving paranormal versus nonparanormal event types this variable was omitted. All other model characteristics were identical to those previously reported with three GLMMs - one per paranormal belief type again performed $^{12}$. Overall, classification accuracy rates for the three follow-up models were very similar to those initially reported, with the six paranormal belief $\times$ thinking style interactions having little, if any, impact on (confirmatory) CE rates. Such trends confirm that baseline differences in NFC and/or FI could not explain believers' higher propensity for making confirmatory CEs.

\subsection{Theoretical Implications}

Current findings suggest stronger paranormal believers are more influenced by - and so make more errors for - conjunctive scenarios containing a confirmatory outcome than those

\footnotetext{
${ }^{12}$ Full details are provided as supplementary data.
} 
who are more sceptical of paranormal claims. With such trends emerging for ESP, PK and LAD believers regardless of event paranormality, it would seem believers are not swayed simply by the presentation of belief-congruent evidence (cf. Russell \& Jones, 1980; Wiseman et al., 2003). As such, current trends replicate paranormal believers proneness to a generic (context free) confirmatory conjunction fallacy first reported by Rogers et al. (2016).

Overall, stronger believers appear to behave in a more normative manner when outcomes are characterised by disconfirmatory evidence, the implication being that they rely more on heuristical (System 1) processes when judging confirmatory conjunctions (cf. Pennycook et al., 2015). However, if believers' preference for intuitive-experiential thinking co-varied straightforwardly with their level and type of paranormal endorsement, one would also expect significant FI $\times$ outcome interactions to emerge. Such interactions were not observed in any of the three belief-based models. Whilst there would be some shared variance between faith in intuition and all three types of paranormal belief (cf. Table 2), individual differences that are unique to FI do not appear to differentially affect the likelihood of paranormal believers making conjunctive errors.

Follow-up analyses incorporating belief $\times$ thinking style interactions confirm that baseline differences in FI had no impact on believers' susceptibility to a (confirmatory) conjunction fallacy. From this it would seem intuitive-experiential (System 1) processing is not the main driver of believers' heightened susceptibility to conjunctive biases, confirmatory or otherwise (cf. Pennycook et al., 2015; Prike et al., 2017). Other factors underlying ESP, PK and LAD beliefs seem to be more relevant.

Instead, the impact paranormal belief had on CE generation depended, to some extent, on respondents' preference for rational-analytic (System 2) thinking (cf. Pennycook et al., 2012). However, this was (marginally) true of just LAD believers. At first glance, current findings suggest individuals who are sceptical of an afterlife and who prefer cognitive engagement 
were less prone to confirmatory CEs - and by implication, had a better (reasoned) understanding of the conjunctive rule - than all other LAD belief $\times$ NFC groups. Presumably motivational factors such as a need to believe (Thalbourne, 1996) were more important for LAD supporters who like to engage in reasoned argument. That said, the low and marginal level of significance $(p=.062)$ coupled with multiple testing means this finding could easily be a statistical artefact. Given the acknowledged limitations of median split analysis (MacCallum, Zhang, Preacher \& Rucker, 2002) conclusions pertaining to the near-significant LAD belief $\times$ NFC interaction reported here should be treated with caution. Replication is required.

Current findings can also be viewed from an inductive confirmation standpoint. According to Tentori et al.'s (2013) Confirmation-Theoretical Framework, CE generation is shaped by the degree to which background information increases the perceived credibility of - that is, inductively confirms - the second constituent event. Here, the magnitude of inductive confirmation is related to the difference between prior probabilities versus posterior probabilities. In Bayesian terms, the prior probability reflects the underlying frequency with which a given event occurs (e.g., the number of people in a total workforce who receive a pay rise on a randomly selected day) and thus represents the base rate likelihood of that event occurring. By comparison, the posterior probability reflects the extent to which some piece of individuating evidence affects the likelihood of the specific event in question (e.g., the extent to which a give employee receives a pay rise if he/she gets a job promotion). As such, it represents the conditional probability of that event occurring.

In the present "motorway" scenario, the prior (base rate) probability reflects the likelihood of Erica car breaking down based on the frequency with which cars of a similar make, model and age break down in general. By contrast, the posterior (conditional) probability reflects the likelihood that Erica's car breaks down given that she feels uneasy about driving it long 
distances (taking account of her supposedly enhanced awareness as to the car's condition). The conjunctive question thus becomes how likely is it that Erica's car will break down given her supposedly enhanced awareness of her car's condition. From a CTF perspective, Erica's sense of uneasiness represents individuating background information with, in the language of CTF, stronger believers making more CEs when background evidence - here, presented as scenario content plus the first constituent - was inductively confirmed (i.e. deemed credible) by the second constituent event. For believers, this was the case regardless of whether background evidence depicted an ostensibly paranormal hence belief-congruent event (Erica's sense of uneasiness supposedly derived from her developing psychic ability) or a clearly non-paranormal thus belief-neutral event (Erica's sense of uneasiness appearing to stem from her developing knowledge of car maintenance $)^{13}$. From this, it is possible stronger paranormal believers are more influenced by the individuating information and more prone to neglecting base rates, (cf. Kahneman \& Tversky, 1973) than non-believers, again regardless of event type. Alternatively, it is possible paranormal sceptics attach too much weight to base rate likelihoods, a tendency known as conservatism (Edwards, Lindman, \& Phillips, 1965). Both forms of over-reliance affect the degree of inductive confirmation and thus the likelihood of (confirmatory) CEs being made. However, at present, support for these claims evidence is mixed with previous studies reported either a positive else no significant relationship between paranormal belief and base rate neglect (Dagnall et al., 2007; 2014; Pennycook et al., 2012; Study 2). Further exploration of believers' fallacy proneness taken from a CTF standpoint seems necessary.

To date, disconfirmatory conjunctions have received limited academic attention with the two fallacy mechanisms suggested by Tversky and Kahneman (1983) both confirmatory in

\footnotetext{
${ }^{13}$ In the present context, belief incongruent evidence would be depicted as paranormal disconfirming rather than non-paranormal scenario content.
} 
nature. In Tversky and Kahneman's $M \rightarrow A$ paradigm background information facilitates the construction of an internalized model (M) which subsequently confirms occurrence of the first constituent event (A) but not the second (B). By extension, the conjunction of events (A and $\mathrm{B}$ ) is also confirmed by $\mathrm{M}$, with this conjunctive outcome deemed more likely than occurrence of the second constituent alone. Such processing forms the basis of Tversky and Kahneman's classic “Linda problem” (see footnote 1). In Tversky and Kahneman’s alternative $A \rightarrow B$ paradigm prior occurrence of the first constituent makes the second seem more likely, with the former providing a plausible explanation of the latter. Thus, for positively conditionally related constituents, the likelihood of CE generation increases (see e.g., Rogers et al., 2017)

Tversky and Kahneman's (1983) two paradigms can both be integrated into Tentori et al.'s (2013) Confirmation-Theoretical Framework. In Tversky and Kahneman's original $M \rightarrow A$ paradigm, each model (M) confirms occurrence of the second constituent event (B). In their alternative $A \rightarrow B$ paradigm, the positive conditional relationship between constituent events means prior occurrence of the first (A) confirms subsequent occurrence of the second (B). In the present study, confirmatory conjunction scenarios correspond to the $A \rightarrow B$ mechanism. Finally, whilst Tversky and Kahneman (1983) acknowledged disconfirmatory conjunctions are possible they provided no explanation for them. Disconfirmatory conjunctions - which are characterised by a negative conditional relationship such that prior occurrence of the first constituent signals non-occurrence of the second $(\mathrm{A} \rightarrow$ not $\mathrm{B})$ - can be accommodated within Tentori et al.'s (2013) CTF. Here, a theoretical A $\rightarrow$ not B mechanism assumed to apply. Indeed, current findings suggest individuals tend to avoid making CEs when confronted by an $\mathrm{A} \rightarrow$ not $\mathrm{B}$ condition, with this being the case regardless of individual differences in their level, and to some extent type, of paranormal belief.

\subsection{Methodological Issues and Ideas for Future Research}


As with previous studies of this ilk (e.g., Rogers et al., 2016; 2017), the current study utilised a general population sample from several UK locations, presented a range of hypothetical conjunction scenarios and retained continuous measures of paranormal belief. Despite these strengths a number of methodological issues remain.

First, the natural logarithmic transformation of PK beliefs has implications for the interpretation of findings (Field, 2013). Having been transformed a one unit increase at the bottom end of the PK beliefs scale will have greater impact on the likelihood of CE generation than a one unit increase at the top end of this scale. Thus, as PK beliefs strengthen the impact such beliefs have on CE incidence becomes progressively weaker. Whether this reflects a genuine trend or is an artefact of the logarithmic transformation itself remains unclear. Either way, it complicates cross-study comparisons (cf. Rogers et al., 2016).

Second, it is possible some disconfirmatory outcomes were not explicit enough in their rejection of the paranormal hypothesis. In the present "inheritance" scenario for instance, being told by a medium [lawyer] that there is a chance of a $£ 1$ million bequest (first constituent) which is then not received (second constituent) may not be deemed an outright disconfirmation of the initial claim because the first constituent was not absolute in its prediction (i.e. did not state there is will definitely be a $£ 1$ million bequest). In principle this could explain the lack of any three-way belief $\times$ event $\times$ outcome interactions. Whilst previous work employing different scenarios suggests this is not the case (Rogers, 2009), future studies should consider such a possibility.

Third, it should also be noted that the sixteen scenarios utilised here reflect a mix of ostensibly paranormal events which included, but were not limited, ESP, PK and LAD (one outlined an apparent out-of-body experience). It is possible different types of paranormal belief interact with scenario content to create individual differences in the extent to which background evidence is deemed plausible hence inductively confirming with, for example, 
stronger ESP believers not necessarily accepting scenarios indicative of an afterlife. Whilst evidence that believers are more prone to confirmatory CEs regardless of whether they endorse ESP, PK or LAD suggests otherwise, future research should examine different paranormal belief types utilising belief-specific conjunctions (e.g., ESP believers should be asked to judge paranormal conjunctions indicative of ESP only). This would provide a more nuanced test of current hypotheses.

Similarly, some scenarios may have been interpreted by different types of paranormal believer as having a different underlying mechanism. For instance, the paranormal version of the "Career" scenario - which depicted a fortune telling - may have been interpreted as an astrological rather than psychic reading (Hines, 2003). Future studies should remove such ambiguities.

As stated in Footnote 3, sceptics are less likely to perceive paranormal scenarios as being credible. Whilst the lack of any event type effect implies this was not an issue the general point remains; where background evidence is viewed as implausible or irrelevant, fallacy generation will be less likely. It is conceivable that believers and sceptics were equally rejecting of background evidence for at least some of the ostensibly paranormal events depicted here. Future research might consider assessing, and perhaps controlling for, the perceived credibility and/or plausibility of scenario content.

Fourth, future studies should explore confirmatory CE proneness in believers who merely report more anomalous experiences versus those who are more incline to attribute paranormal causation to anomalous events (Irwin, Dagnall \& Drinkwater, 2013). Following Prike et al. (2017) the former seem more likely to make confirmatory CEs than the latter.

Other types of thinking disposition such as inflexible, dogmatic or absolutist thinking (e.g., Stanovich \& West, 1998) could also be tested in the current context. That said, it has recently been argued that limitations in peoples' metacognitive awareness mean self-report 
measures such as the NFC and FI are a poor measure of peoples' actual thinking style and that behavioural (objective) measures of heuristical processing - such as Toplak et al.'s (2011) heuristics and biases battery - should be employed instead (Pennycook, Ross, Koehler \& Fugelsang, 2017). Such argument calls into question the external validity of the NFC and FI subscales. Future studies employing the self-report thinking style measures should bear such criticism in mind. Relatedly, the extent to which believers' susceptibility to confirmatory CEs reflect their broader misperception of randomness should be tested by including appropriate, behaviourally-based randomness judgement tasks (cf. Dagnall et al., 2014).

Finally, the proportion of non-Caucasian respondents sampled here was relatively low (6.8\%) meaning current findings have limited generalisability in terms of ethnic background. With ethnicity known to impact on the levels and type of paranormal endorsement (French \& Stone, 2014; Irwin, 2009), future research should aim for more representative sampling.

\subsection{Conclusion}

Current findings replicate previous claims that paranormal believers are especially prone to a generic (context free) and confirmatory conjunction fallacy, extending these trends more robustly to LAD believers too. Such biases were found to exist regardless of individual differences in thinking style preference hence the tendency either to shun analytic (System 2) reasoning and/or rely on intuitive (System 1) processes when judging conjunctive events. Consistent with Tentori et al.’s (2013) Confirmation-Theoretical Framework, it seems paranormal believers are for some reason more influenced by inductively confirming background evidence than are paranormal sceptics. More research is needed to further explore the precise psychological mechanisms underlying this seemingly robust effect.

\section{References}


Bouvet, R., \& Bonnefon, J. (2015). Non-reflective thinkers are predisposed to attribute supernatural causation to uncanny experiences. Personality \& Social Psychology Bulletin, 41(7), 955-961. doi:10.1177/0146167215585728.

Brotherton, R., \& French, C.C. (2014). Belief in conspiracy theories and susceptibility to the conjunction fallacy. Applied Cognitive Psychology, 28(2), 238-248. doi. 10.1002/acp.2995.

Buchner, A., Erdfelder, E., Faul, F., \& Lang, A-G. (1992-2008). G*Power Version 2.0.10. Available from http://download.cnet.com/G-Power/3000-2054_4-10647044.html [Last accessed 31 December 2017].

Dagnall, N., Denovan, A., Drinkwater, K., Parker, A., \& Clough, P. (2016). Toward a better understanding of the relationship between belief in the paranormal and statistical bias: The potential role of schizotypy. Frontiers in Psychology, 7, 1-14. doi: 10.3389/fpsyg.2016.01045.

Dagnall, N., Drinkwater, K., Denovan, A., Parker, A., \& Rowley, K. (2016). Misperception of chance, conjunction, framing effects and belief in the paranormal: A further evaluation. Applied Cognitive Psychology, 30(3), 409-419. doi:10.1002/acp.3217.

Dagnall, N., Drinkwater, K., Parker, A., \& Rowley, K. (2014). Misperception of chance, conjunction, belief in the paranormal and reality testing: A reappraisal. Applied Cognitive Psychology, 28(5), 711-719. doi:10.1002/acp.3057.

Dagnall, N., Parker, A., \& Munley, G. (2007). Paranormal belief and reasoning. Personality \& Individual Differences, 43(6), 1406-1415. doi: 10.1016/j.paid.2007.04.017.

De Neys, W., \& Bonnefon, J. (2013). The 'whys' and 'whens' of individual differences in thinking biases. Trends in Cognitive Sciences, 17(4), 172-178.

doi:10.1016/j.tics.2013.02.001. 
Edwards, W., Lindman, H., \& Phillips L.D. (1965). Emerging technologies for making decisions. New Directions in Psychology, 2, 265-325.

Epstein, S. (2013). Cognitive-experiential self-theory: An integrative theory of personality. In I. B. Weiner, H. A. Tennen, \& J. A. Suls.(Eds.) Handbook of psychology: Personality \& social psychology, Vol. 5 (2nd edition) (pp. 93-118). Hoboken, NJ, US: Wiley \& Sons.

Epstein, S., Denes-Raj, V., \& Pacini, R. (1995). The Linda problem revisited from the perspective of cognitive-experiential self-theory. Personality \& Social Psychology Bulletin, 21(11), 1124-1138. doi:10.1177/01461672952111001.

Epstein, S., Pacini, R., Denes-Raj, V., \& Heier, H. (1996). Individual differences in intuitiveexperiential and analytical-rational thinking styles. Journal of Personality \& Social Psychology, 71(2), 390-405. doi:10.1037/0022-3514.71.2.390

Evans, J. St. B. T. \& Stanovich, K.E. (2013). Dual-process theories of higher cognition: Advancing the debate. Perspectives on Psychological Science 8(3), 223-241. doi: $10.1177 / 1745691612460685$.

Field, A. (2013). Discovering statistics using SPSS (5th edition). London, UK: Sage.

Fisk, J. E. (2017). Conjunction fallacy. In R. F. Pohl (Ed.). Cognitive illusions: Intriguing phenomena in judgement, thinking and memory (2nd edition). (pp. 25-43). London, UK: Routledge.

French. C.C., \& Stone, A. (2014). Anomalistic psychology: Exploring paranormal belief and experience. London: Palgrave Macmillan.

Gray, S. J., \& Gallo, D. A. (2016). Paranormal psychic believers and skeptics: A large-scale test of the cognitive differences hypothesis. Memory \& Cognition, 44(2), 242-261. doi:10.3758/s13421-015-0563-x. 
Hadlaczky, G. \& Westerlund, J. (2011). Sensitivity to coincidences and paranormal belief. Perceptual \& Motor Skills, 113(3), 894-908. doi: 10.2466/09.22.PMS.113.6.894-908 ISSN 0031-5125.

Hines, T. (2003). Pseudoscience and the paranormal (2nd edition). Amherst, New York: Prometheus.

Irwin, H. J. (2009). The psychology of paranormal belief: A researcher's handbook. Hatfield, Hertfordshire: University of Hertfordshire Press.

Irwin, H. J. (2015). Thinking style and the making of a paranormal disbelief. Journal of the Society for Psychical Research, 79(920[3]), 129-139.

Irwin, H. J., Dagnall, N., \& Drinkwater, K. (2013). Parapsychological experience as anomalous experience plus paranormal attribution: A questionnaire based on a new approach to measurement. Journal of Parapsychology, 77, 39-53.

Irwin, H. J., \& Watt, C. A. (2007). An introduction to parapsychology (5th edition). Jefferson, NC, US: McFarland.

Irwin, H. J., \& Wilson, K. (2013). Anomalous experiences and the intuitive-experiential style of thinking. Journal of the Society for Psychical Research, 77.2(911), 65-71.

Kahneman, D., (2011). Thinking fast \& slow. London, UK: Penguin

Kahneman, D., \& Tversky, A. (1973). On the psychology of prediction. Psychological Review, 80(4), 237-251. doi:10.1037/h0034747.

Lobato, E., Mendoza, J., Sims, V., \& Chin, M. (2014). Examining the relationship between conspiracy theories, paranormal beliefs, and pseudoscience acceptance among a university population. Applied Cognitive Psychology, 28(5), 617-625. doi: 10.1002/acp.3042.

Majima, Y. (2015). Belief in pseudoscience, cognitive style and science literacy. Applied Cognitive Psychology, 29(4), 552-559. doi:10.1002/acp.3136. 
MacCallum, R. C., Zhang, S., Preacher, K.J. \& Rucker, D.D. (2002). On the practice of dichotomization of quantitative variables. Psychological Methods, 7(1), 19-40. doi: 10.1037//1082-989X.7.1.19.

Norušis, M. J. (2007). SPSS 15.0 Advances Statistical Procedures Companion. Upper Saddle River, NJ, US: Prentice Hall.

Pennycook, G., Cheyne, J. A., Seli, P., Koehler, D. J., \& Fugelsang, J. A. (2012). Analytic cognitive style predicts religious and paranormal belief. Cognition, 128(3), 335-346. doi: 10.1016/j.cognition.2012.03.003.

Pennycook, G., Cheyne, J. A., Barr, N., Koehler, D. J., \& Fugelsang, J. A. (2015). On the reception and detection of pseudo-profound bullshit. Judgment \& Decision Making, 10(6), $549-563$.

Pennycook, G., Ross, R. M., Koehler, D. J., \& Fugelsang, J. A. (2017). Dunning-Kruger effects in reasoning: Theoretical implications of the failure to recognize incompetence. Psychonomic Bulletin \& Review, 24(6), 1774-1784. doi:10.3758/s13423-017-1242-7

Phillips, W. J., Fletcher, J. M., Marks, A. G., \& Hine, D. W. (2016). Thinking styles and decision making: A meta-analysis. Psychological Bulletin, 142(3), 260-290. doi:10.1037/bul0000027.

Prike, T., Arnold, M. M., \& Williamson, P. (2017). Psychics, aliens, or experience? Using the Anomalistic Belief Scale to examine the relationship between type of belief and probabilistic reasoning. Consciousness \& Cognition, 53, 151-164. ·doi: 10.1016/j.concog.2017.06.003.

Rogers, P., (2015). The probabilistic reasoning bias hypothesis of belief in the paranormal: A review. In N. Galbraith (Ed.). Aberrant beliefs and thinking. Hove, UK: Psychology Press.

Rogers, P. Davis, T., \& Fisk, J. (2009). Paranormal belief and susceptibility to the conjunction fallacy. Applied Cognitive Psychology, 23(4), 524-542. doi:10.1002/acp.1472 
Rogers, P., Fisk, J. E., \& Lowrie, E. L. (2016). Paranormal believers’ susceptibility to errors for confirmatory vs. disconfirmatory conjunctions. Applied Cognitive Psychology. doi: 10.1002/acp.3222

Rogers, P., Fisk, J. E., \& Lowrie, E. L. (2017). The role of constituent conditional relatedness in paranormal believers' susceptibility to the conjunction fallacy. Consciousness \& Cognition, 56, 13-29. doi: 10.1016/j.concog.2017.09.010.

Rogers, P. Fisk, J., \& Wiltshire, D. (2011). Paranormal belief and the conjunction fallacy: Controlling for temporal relatedness and potential surprise differentials in component events. Applied Cognitive Psychology, 24, 1-20. doi: 10.1002/acp.1732.

Russell, D., \& Jones, W. H. (1980). When superstition fails: Reactions to disconfirmation of paranormal beliefs. Personality \& Social Psychology Bulletin, 6(1), 83-88. doi:10.1177/014616728061012.

Stanovich, K. E., \& West, R. F. (1998). Individual differences in rational thought. Journal of Experimental Psychology: General, 127(2),161-188. doi:10.1037/0096-3445.127.2.161.

Stanovich, K. E., \& West, R. F. (2000). Individual differences in reasoning: Implications for the rationality debate?. Behavioral \& Brain Sciences, 23(5), 645-665. doi:10.1017/S0140525X00003435.

Tentori, K., Crupi, V., \& Russo, S. (2013). On the determinants of the conjunction fallacy: probability versus inductive confirmation. Journal of Experimental Psychology: General, 142(1), 235-255. doi: 10.1037/a0028770.

Thalbourne, M. A. (1996). Belief in life after death: Psychological origins and influences, Personality \& Individual Differences, 21(6), 1043-1045. doi:10.1016/S01918869(96)00167-5.

Thalbourne, M. A. (2010). The Australian Sheep-Goat Scale: Development and empirical findings. Australian Journal of Parapsychology, 10(1), 5-39. 
Thalbourne, M. A., \& Delin. P. S. (1993). A new instrument for measuring the sheep-goat variable: Its psychometric properties and factor structure. Journal of Society for Psychical Research, 59, 172-186.

Toplak, M., West, R., \& Stanovich, K. (2011). The Cognitive Reflection Test as a predictor of performance on heuristics-and-biases tasks. Memory \& Cognition, 39(7), 1275-1289. doi:10.3758/s13421-011-0104-1

Toyosawa, J., \& Karasawa, K. (2004). Individual differences on judgment using the ratio-bias and the Linda problem: Adopting CEST and Japanese version of REI. Japanese Journal of Social Psychology, 20(2), 85-92. [English Abstract].

Tversky, A., \& Kahneman, D. (1983). Extensional versus intuitive reasoning: The conjunction fallacy in probability judgement. Psychological Review, 90(4), 293-315. doi: 10.1037/0033-295X.90.4.293.

Twisk, J. W. R. (2006). Applied multivariate analysis: A practical guide. Cambridge, UK: Cambridge University Press.

Wiseman, R., Greening, E., \& Smith, M. (2003). Belief in the paranormal and suggestion in the séance room. British Journal of Psychology, 94(3), 285-297. doi:10.1348/000712603767876235.

Wiseman, R., \& Watt, C. (2006). Belief in psychic ability and the misattribution hypothesis: A qualitative review. British Journal of Psychology, 97(3), 323-338. doi: $10.1348 / 000712605 \times 72523$.

Wolfradt, U., Oubaid, V., Straube, E. R., Bischoff, N., \& Mischo, J. (1999). Thinking styles, schizotypal traits and anomalous experiences. Personality \& Individual Differences, 27(5), 821-830. doi:10.1016/S0191-8869(99)00031-8. 
Running Head: PARANORMAL BELIEF, THINKING STYLE \& CONFIRMATORY CONJUNCTION ERRORS

\section{Acknowledgements}

The authors would like to thank all anonymous reviewers for their useful comments regarding earlier drafts of this manuscript. 
Table 1: Internal Reliability, Descriptive, Normality \& Skew Statistics for All Measures (Final Versions) ${ }^{\dagger}$

\begin{tabular}{|c|c|c|c|c|c|c|c|c|c|c|c|c|c|c|c|}
\hline \multirow[b]{2}{*}{ Scale } & \multirow[b]{2}{*}{ Subscale } & \multicolumn{2}{|c|}{ Reliability } & \multicolumn{4}{|c|}{ Descriptives } & \multicolumn{4}{|c|}{ Normality } & \multicolumn{4}{|c|}{ Skew } \\
\hline & & No. Items & $\alpha$ & $M$ & $(S D)$ & Obs. Range & Median & $K-S$ & $d f$ & $p$ & & $I S$ & $(S E)$ & $Z$ & $I S$ \\
\hline \multirow[t]{3}{*}{ ASGS } & ESP & 10 & .93 & 3.43 & (1.47) & 1.00 to 7.00 & 3.50 & .07 & 256 & .002 & $* *$ & .12 & .15 & .81 & \\
\hline & PK & 05 & .90 & 2.59 & $(1.56)$ & 1.00 to 7.00 & 2.20 & .15 & 253 & .000 & $* * *$ & .68 & .15 & 4.39 & $* * *$ \\
\hline & LAD & 03 & .76 & 3.55 & (1.64) & 1.00 to 7.00 & 3.67 & .08 & 256 & .001 & $* *$ & .08 & .15 & .50 & \\
\hline \multirow[t]{2}{*}{ REI } & Need For Cognition & 18 & .86 & 4.44 & $(.88)$ & 2.00 to 7.00 & 4.33 & .07 & 251 & .010 & * & .23 & .15 & 1.51 & \\
\hline & Faith in Intuition & 11 & .85 & 4.86 & (.93) & 1.27 to 6.82 & 4.91 & .07 & 251 & .005 & $* *$ & -.50 & .15 & -3.25 & $* * *$ \\
\hline
\end{tabular}

${ }^{\dagger}$ Data for final versions of each subscale; internal reliability given by Cronbach's alpha $(\alpha)$ coefficient; potential ranges from 1:00 to 7:00; normality indicated by Kolmogorov-Smirnov $(K-S)$ tests. Significant at the *p<.05 ** $<<.01$ and $* * *$ p $<.001$ levels; $a=$ approaches significance (two-tailed; $n=251$ to 256 ). ${ }^{\ddagger}$ Subscale subsequently omitted. PK belief ratings subsequently transformed. 
Table 2: Correlations (r) between Conjunction Error Rate, Thinking Style \& Demographic Measures ${ }^{\dagger}$

\begin{tabular}{|c|c|c|c|c|c|c|c|c|c|c|c|c|c|}
\hline Scale & Subscale & \multicolumn{2}{|c|}{ Total CEs } & \multicolumn{2}{|c|}{ ESP } & \multicolumn{2}{|c|}{$\mathrm{PK}$} & \multicolumn{2}{|c|}{ LAD } & \multicolumn{2}{|c|}{ NFC } & \multicolumn{2}{|c|}{ FI } \\
\hline CEs & Total & & & & & & & & & & & & \\
\hline \multirow{3}{*}{ ASGS } & ESP & .24 & $* * *$ & & & & & & & & & & \\
\hline & PK & .19 & $* * *$ & .82 & $* * *$ & & & & & & & & \\
\hline & LAD & .22 & $* * *$ & .80 & $* * *$ & .71 & $* * *$ & & & & & & \\
\hline \multirow[t]{2}{*}{ REI } & NFC & -.08 & $* * *$ & -.24 & $* * *$ & -.29 & $* * *$ & -.24 & $* * *$ & & & & \\
\hline & FI & .10 & $* * *$ & .30 & $* * *$ & .24 & $* * *$ & .34 & $* * *$ & .06 & $* * *$ & & \\
\hline \multirow[t]{6}{*}{ Demogs } & Gender $^{\dagger}$ & .07 & $* * *$ & .18 & $* * *$ & .12 & $* * *$ & .25 & $* * *$ & -.11 & $* * *$ & .09 & $* * *$ \\
\hline & Age & .06 & $* *$ & -.07 & $* * *$ & -.11 & $* * *$ & -.06 & ** & -.01 & & .01 & \\
\hline & Ethnicity $^{\dagger}$ & .02 & & -.05 & ** & -.08 & $* * *$ & -.03 & & .06 & $* * *$ & .03 & \\
\hline & Occupation $^{\dagger}$ & .00 & & -.05 & $* *$ & -.05 & $* *$ & -.04 & * & .02 & & -.04 & $*$ \\
\hline & Quals (gen) & .00 & & -.17 & $* * *$ & -.16 & $* * *$ & -.15 & $* * *$ & .35 & $* * *$ & -.04 & * \\
\hline & Quals $(\mathrm{m} / \mathrm{s} / \mathrm{p})$ & -.02 & & -.05 & $* *$ & -.01 & & -.05 & $* *$ & .19 & $* * *$ & -.01 & \\
\hline
\end{tabular}

†Total CEs across all conditions; PK Beliefs subjected to natural logarithmic transformation; for dichotomous demographic measures higher scores reflect female gender, Caucasian ethnicity and student occupational status; the suffix $\mathrm{m} / \mathrm{s} / \mathrm{p}=$ maths/statistics $/ \mathrm{psychology}$; associations with one dichotomous measure given by $r_{\mathrm{pb}}$; associations between two dichotomous measures given by $p h i$. Significant effects at the $* p<.05 * * p<.01$ and *** $p<.001$ level ; $a=$ approaches significance (two-tailed; $n=219-255$ ). 


\begin{tabular}{|c|c|c|c|c|c|c|c|c|c|}
\hline \multirow{2}{*}{$\begin{array}{l}\text { Scale } \\
\text { Demogs }\end{array}$} & \multirow{2}{*}{$\begin{array}{l}\text { Subscale } \\
\text { Gender }^{\dagger}\end{array}$} & \multicolumn{2}{|c|}{ Gender } & \multicolumn{2}{|c|}{ Age } & $\begin{array}{c}\text { Ethnicity } \\
\text { (Caucasian) }\end{array}$ & \multirow[t]{2}{*}{$\begin{array}{c}\text { Occupation } \\
\text { (student) }\end{array}$} & \multirow[t]{2}{*}{$\begin{array}{c}\text { Qualifications } \\
\text { (general) }\end{array}$} & \multirow[t]{2}{*}{$\begin{array}{c}\text { Qualifications } \\
(\mathrm{m} / \mathrm{s} / \mathrm{p})\end{array}$} \\
\hline & & & & & & & & & \\
\hline & Age & -.05 & $* *$ & & & & & & \\
\hline & Ethnicity $^{\dagger}$ & .08 & $* * *$ & .06 & $* * *$ & & & & \\
\hline & Occupation $^{\dagger}$ & .00 & & -.38 & $* * *$ & .01 & & & \\
\hline & Quals (gen) & -.10 & *** & -.05 & ** & $-.05 \quad * *$ & -.03 & & \\
\hline & Quals $(\mathrm{m} / \mathrm{s} / \mathrm{p})$ & -.15 & $* * *$ & -.17 & $* * *$ & $-.03 \quad a$ & $.06 \quad * *$ & $.61 \quad * * *$ & \\
\hline
\end{tabular}

†Total CEs across all conditions; PK Beliefs subjected to natural logarithmic transformation; for dichotomous demographic measures higher scores reflect female gender, Caucasian ethnicity and student occupational status; the suffix $\mathrm{m} / \mathrm{s} / \mathrm{p}=$ maths/statistics/psychology; associations with one dichotomous measure given by $r_{\mathrm{p}}$; associations between two dichotomous measures given by $p h i$. Significant effects at the $* p<.05 * * p<.01$ and *** $p<.001$ level ; $a=$ approaches significance (two-tailed; $n=219-255$ ). 
Table 3: Correlations (r) between Conjunction Error Rate, Thinking Style \& Demographics across Event \& Outcome Types ${ }^{\dagger}$

\begin{tabular}{|c|c|c|c|c|c|c|c|c|c|c|c|c|c|c|c|c|c|c|c|}
\hline \multirow{3}{*}{$\begin{array}{l}\text { Scale } \\
\text { ASGS }\end{array}$} & \multirow{3}{*}{$\begin{array}{l}\text { Subscale } \\
\text { ESP }\end{array}$} & \multicolumn{6}{|c|}{ Paranormal } & \multicolumn{6}{|c|}{ Non-paranormal } & \multicolumn{6}{|c|}{ All } \\
\hline & & \multicolumn{2}{|c|}{ Confirm } & \multicolumn{2}{|c|}{ Disconfirm } & \multicolumn{2}{|c|}{ All } & \multicolumn{2}{|c|}{ Confirm } & \multicolumn{2}{|c|}{ Disconfirm } & \multicolumn{2}{|c|}{ All } & \multicolumn{2}{|c|}{ Confirm } & \multicolumn{2}{|c|}{ Disconfirm } & \multicolumn{2}{|c|}{ All } \\
\hline & & .29 & $* * *$ & .05 & ** & .20 & $* * *$ & .28 & $* * *$ & .11 & $* * *$ & .23 & $* * *$ & .33 & $* * *$ & .10 & $* * *$ & .24 & $* * *$ \\
\hline & PK & .27 & $* * *$ & .01 & & .17 & $* * *$ & .23 & $* * *$ & .07 & $* * *$ & .18 & $* * *$ & .29 & $* * *$ & .05 & $* *$ & .19 & $* * *$ \\
\hline & LAD & .30 & $* * *$ & .04 & $*$ & .20 & $* * *$ & .27 & $* * *$ & .08 & $* * *$ & .20 & $* * *$ & .33 & $* * *$ & .07 & $* * *$ & .22 & $* * *$ \\
\hline \multirow[t]{2}{*}{ REI } & NFC & -.21 & $* * *$ & -.01 & & -.13 & $* * *$ & -.10 & $* * *$ & .05 & $* *$ & -.03 & $a$ & -.17 & $* * *$ & .02 & & -.08 & $* * *$ \\
\hline & FI & .17 & $* * *$ & .03 & & .12 & $* * *$ & .07 & $* * *$ & .03 & $a$ & .06 & $* * *$ & .13 & $* * *$ & .03 & * & .10 & $* * *$ \\
\hline \multirow[t]{6}{*}{ Demogs } & Gender $^{\dagger}$ & .08 & $* * *$ & .03 & $a$ & .07 & $* * *$ & .07 & $* * *$ & .07 & $* * *$ & .08 & $* * *$ & .08 & $* * *$ & .05 & $* *$ & .07 & $* * *$ \\
\hline & Age & -.08 & $* * *$ & .09 & $* * *$ & .01 & & .04 & $*$ & .13 & $* * *$ & .10 & $* * *$ & -.02 & & .13 & $* * *$ & .06 & $* *$ \\
\hline & Ethnicity $^{\dagger}$ & -.03 & & .03 & $a$ & .00 & & -.05 & $* *$ & .10 & $* * *$ & .03 & $*$ & -.04 & $* *$ & .08 & $* * *$ & .02 & \\
\hline & Occupation $^{\dagger}$ & -.02 & & -.04 & ** & -.04 & $*$ & .05 & $* *$ & .00 & & .03 & & .02 & & -.03 & & .00 & \\
\hline & Quals (gen) & -.13 & $* * *$ & .12 & $* * *$ & .00 & & .00 & & .03 & $a$ & .02 & & -.07 & $* * *$ & .08 & $* * *$ & .00 & \\
\hline & Quals $(\mathrm{m} / \mathrm{s} / \mathrm{p})$ & -.08 & $* * *$ & .05 & $* *$ & -.01 & & .01 & & -.05 & $* *$ & -.02 & & -.03 & $a$ & .00 & & -.02 & \\
\hline
\end{tabular}

${ }^{\dagger}$ Conjunction error rate reflects total number of CEs made across relevant scenarios; PK Beliefs subjected to natural logarithmic transformation; for dichotomous demographic measures higher scores reflect female gender, Caucasian ethnicity and student occupational status; the suffix m/s/p = maths/statistics/psychology; associations with one dichotomous measure given by $r_{\mathrm{pb}}$; associations between two dichotomous measures given by $p h i$. Significant effects at the $* p<.05 * * p<.01$ and $* * * p<.001$ level; $a=$ approaches significance (two-tailed; cases from 3,424 to 4,106) 
Table 4: Percentage of Conjunction Errors, Non-Errors \& All Responses Correctly Predicted by Paranormal Belief \& Intercept Types ${ }^{\dagger}$

\begin{tabular}{|c|c|c|c|c|}
\hline Response & Intercept & ESP & PK & LAD \\
\hline Type & Type & $(\%)$ & $(\%)$ & $(\%)$ \\
\hline \multirow[t]{2}{*}{ Errors } & Fixed & 19.6 & 16.0 & 17.2 \\
\hline & Random & 58.2 & 57.7 & 58.3 \\
\hline \multirow[t]{2}{*}{ Non-errors } & Fixed & 88.3 & 89.9 & 89.1 \\
\hline & Random & 80.0 & 80.8 & 81.0 \\
\hline \multirow[t]{2}{*}{ All } & Fixed & 59.4 & 58.9 & 58.9 \\
\hline & Random & 70.8 & 71.1 & 71.5 \\
\hline
\end{tabular}

${ }^{\dagger}$ PK Beliefs subjected to natural logarithmic transformation; models with first order auto-regressive (AR1) covariance structure; figures to one decimal place ( $n=3,777$ to 3,793 cases). 
Table 5: Predictors of Conjunction Error Generation (Presence vs. Absence) by Paranormal Belief Type ${ }^{\dagger}$

\begin{tabular}{|c|c|c|c|c|c|c|c|c|c|c|c|c|c|c|c|c|c|c|c|c|c|}
\hline \multirow[b]{3}{*}{ Predictor } & \multicolumn{7}{|c|}{ ESP } & \multicolumn{7}{|c|}{ PK } & \multicolumn{7}{|c|}{ LAD } \\
\hline & \multirow[b]{2}{*}{$b$} & \multirow[b]{2}{*}{$t$} & \multirow[b]{2}{*}{$p$} & & \multirow[b]{2}{*}{$\exp (b)$} & \multicolumn{2}{|c|}{$95 \% C I$} & \multirow[b]{2}{*}{$b$} & \multirow[b]{2}{*}{$t$} & \multirow[b]{2}{*}{$p$} & & \multirow[b]{2}{*}{$\exp (b)$} & \multicolumn{2}{|c|}{$95 \% C I$} & \multirow[b]{2}{*}{$b$} & \multirow[b]{2}{*}{$t$} & \multirow[b]{2}{*}{$p$} & & \multirow[b]{2}{*}{$\exp (b)$} & \multicolumn{2}{|c|}{$95 \% C I$} \\
\hline & & & & & & Lwr & Upr & & & & & & Lwr & $\mathrm{Upr}$ & & & & & & Lwr & Upr \\
\hline Random Intercept & 1.07 & .52 & .601 & & 2.92 & .05 & 161.43 & .95 & .46 & .649 & & 2.59 & .04 & 154.54 & .78 & .38 & .706 & & 2.18 & .04 & 124.79 \\
\hline Gender & -.13 & -.86 & .393 & & .88 & .66 & 1.18 & -.16 & -1.09 & .276 & & .85 & .63 & 1.14 & -.10 & -.64 & .524 & & .91 & .68 & 1.22 \\
\hline Age & .04 & .72 & .471 & & 1.05 & .93 & 1.18 & .04 & .64 & .522 & & 1.04 & .92 & 1.18 & .04 & .58 & .563 & & 1.04 & .92 & 1.17 \\
\hline Event (E) & .17 & 1.64 & .101 & & 1.18 & .97 & 1.44 & .18 & 1.73 & .084 & & 1.19 & .98 & 1.45 & .17 & 1.67 & .095 & & 1.19 & .97 & 1.45 \\
\hline Outcome (O) & .06 & .63 & .531 & & 1.06 & .88 & 1.29 & .06 & .55 & .581 & & 1.06 & .87 & 1.28 & .06 & .60 & .548 & & 1.06 & .87 & 1.29 \\
\hline $\mathrm{E} \times \mathrm{O}$ & -.19 & -1.33 & .185 & & .83 & .63 & 1.10 & -.20 & -1.38 & .169 & & .82 & .62 & 1.09 & -.19 & -1.31 & .189 & & .83 & .63 & 1.10 \\
\hline Belief (B) & .28 & 3.87 & $<.001$ & $* * *$ & 1.32 & 1.15 & 1.53 & 1.15 & 2.99 & .003 & $* *$ & 3.16 & 1.49 & 6.71 & .24 & 3.53 & $<.001$ & $* * *$ & 1.27 & 1.11 & 1.44 \\
\hline $\mathrm{B} \times \mathrm{E}$ & .02 & .31 & .754 & & 1.03 & .88 & 1.19 & .05 & .12 & .905 & & 1.05 & .48 & 2.32 & .01 & .14 & .892 & & 1.01 & .88 & 1.16 \\
\hline $\mathrm{B} \times \mathrm{O}$ & -.27 & -3.62 & $<.001$ & $* * *$ & .76 & .66 & .88 & -1.38 & -3.49 & $<.001$ & $* * *$ & .25 & .12 & .55 & -.25 & -3.72 & $<.001$ & $* * *$ & .78 & .68 & .89 \\
\hline $\mathrm{B} \times \mathrm{E} \times \mathrm{O}$ & .11 & 1.04 & .296 & & 1.12 & .91 & 1.38 & .50 & .87 & .383 & & 1.64 & .54 & 5.01 & .08 & .82 & .415 & & 1.08 & .89 & 1.31 \\
\hline NFC & -.29 & -2.51 & .012 & $*$ & .75 & .60 & .94 & -.30 & -2.55 & .011 & * & .74 & .59 & .93 & -.30 & -2.54 & .011 & * & .74 & .59 & .94 \\
\hline $\mathrm{NFC} \times \mathrm{E}$ & .19 & 1.58 & .113 & & 1.21 & .96 & 1.52 & .18 & 1.48 & .138 & & 1.20 & .94 & 1.51 & .18 & 1.52 & .128 & & 1.20 & .95 & 1.52 \\
\hline $\mathrm{NFC} \times \mathrm{O}$ & .22 & 1.90 & .058 & $a$ & 1.25 & .99 & 1.56 & .21 & 1.76 & .079 & $a$ & 1.23 & .98 & 1.55 & .21 & 1.84 & .067 & $a$ & 1.24 & .99 & 1.54 \\
\hline $\mathrm{NFC} \times \mathrm{E} \times \mathrm{O}$ & -.01 & -.03 & .976 & & 1.00 & .72 & 1.38 & .00 & .00 & .997 & & 1.00 & .72 & 1.39 & -.01 & -.08 & .936 & & .99 & .71 & 1.37 \\
\hline FI & .17 & 1.35 & .178 & & 1.19 & .93 & 1.52 & .24 & 1.90 & .057 & $a$ & 1.27 & .99 & 1.62 & .17 & 1.35 & .177 & & 1.19 & .93 & 1.53 \\
\hline $\mathrm{FI} \times \mathrm{E}$ & -.21 & -1.59 & .111 & & .81 & .62 & 1.05 & -.21 & -1.57 & .117 & & .81 & .63 & 1.05 & -.21 & -1.52 & .128 & & .81 & .62 & 1.06 \\
\hline $\mathrm{FI} \times \mathrm{O}$ & -.09 & -.69 & .488 & & .91 & .71 & 1.18 & -.13 & -1.45 & .296 & & .88 & .98 & 1.12 & -.08 & -.57 & .567 & & .93 & .72 & 1.20 \\
\hline $\mathrm{FI} \times \mathrm{E} \times \mathrm{O}$ & .15 & .79 & .431 & & 1.16 & .80 & 1.68 & .18 & .96 & .337 & & 1.19 & .83 & 1.71 & .16 & .86 & .391 & & 1.18 & .81 & 1.71 \\
\hline AR1 Diagonal ${ }^{\ddagger}$ & .92 & 39.59 & $<.001$ & $* * *$ & -- & .88 & .97 & .92 & 39.48 & $<.001$ & $* * *$ & -- & .88 & .97 & .92 & 39.55 & $<.001$ & $* * *$ & -- & .88 & .97 \\
\hline AR1 Rho & .04 & 2.31 & .021 & $*$ & -- & .01 & .08 & .05 & 2.34 & .019 & $*$ & -- & .01 & .08 & .05 & 2.45 & .014 & * & -- & .01 & .08 \\
\hline
\end{tabular}

${ }^{\dagger}$ Figures for model with AR1 structure and random intercept; PK Beliefs subjected to natural logarithmic transformation; all continuous measures subjected to grand means centering; higher scores reflect female gender; inferential statistic for ARI Rho (intraclass correlation coefficient) and ARI Diagonal (estimated variance) is $Z$ rather than $t$. Significant effects at the * $p<.05 * * p<.01$ and $* * * *<.001$ level; $a=a p p r o a c h e s$ significance (two-tailed; $n=3,478$ to 3,494 cases) 
Supplementary Table 1: GLMM Goodness-of-Fit Statistics for Conjunction Error Generation (Presence vs. Absence) by Covariance Structure \& Paranormal Belief Types $^{\dagger}$

\begin{tabular}{|c|c|c|c|c|c|c|}
\hline \multirow{2}{*}{$\begin{array}{l}\text { Covariance } \\
\text { Structure }\end{array}$} & \multicolumn{2}{|c|}{ ESP } & \multicolumn{2}{|c|}{$\mathrm{PK}_{\mathrm{LOG}}$} & \multicolumn{2}{|c|}{ LAD } \\
\hline & $-2 \mathrm{LL}$ & AIC & $-2 \mathrm{LL}$ & AIC & $-2 \mathrm{LL}$ & $\mathrm{AIC}$ \\
\hline Scaled Identity. & $15,577.25$ & $15,577.25$ & $15,497.15$ & $15,501.15$ & $15,583.53$ & $15,587.53$ \\
\hline Diagonal. & $15,626.70$ & $15,626.70$ & $15,549.08$ & $15,583.25$ & $15,630.32$ & $15,664.49$ \\
\hline First Order Auto-Regressive (AR1) & $15,512.51$ & $15,518.52$ & $15,430.52$ & $15,436.53$ & $15,514.33$ & $15,520.34$ \\
\hline Compound Symmetry (CS) & -- & -- & -- & -- & -- & -- \\
\hline
\end{tabular}

${ }^{\dagger}$ PK Beliefs subjected to natural logarithmic transformation; full models with random intercept and first order auto-regressive (AR1) covariance structures; model goodness-of-fit and complexity-corrected goodness-of-fit given by -2 Log Likelihood (-2LL) and Akaike's Information Criteria (AIC) respectively; PK Beliefs subjected to natural logarithmic transformation; figures to 2 decimal places; smaller figures indicate better model fit; all compound symmetry structures failed to converge (FTC) ( $n=3,777$ to 3,793 cases). 
Running Head: PARANORMAL BELIEF, THINKING STYLE \& CONJUNCTION ERRORS

Supplementary Table 2: GLMM Goodness-of-Fit \& -2LL Change Statistics for Conjunction Error Generation (Presence vs. Absence) by Paranormal Belief \& Model Types ${ }^{\dagger}$

\begin{tabular}{|c|c|c|c|c|c|c|c|c|c|c|c|c|c|c|}
\hline \multirow[b]{2}{*}{ Step } & \multirow[b]{2}{*}{ Predictor(s) Entered } & \multirow{2}{*}{$\begin{array}{c}\text { Fit } \\
\text { Index } \\
\end{array}$} & \multicolumn{4}{|c|}{ ESP } & \multicolumn{4}{|c|}{ PK } & \multicolumn{4}{|c|}{ LAD } \\
\hline & & & $x^{2}$ & $\Delta \chi^{2}$ & $p$ & & $\chi^{2}$ & $\Delta \chi^{2}$ & $p$ & & $x^{2}$ & $\Delta \chi^{2}$ & $p$ & \\
\hline \multirow[t]{2}{*}{00.} & No intercept & $-2 \mathrm{LL}$ & $16,024.12$ & -- & -- & & $16,024.12$ & -- & -- & & $16,024.12$ & -- & -- & \\
\hline & & AIC & $16,028.22$ & -- & -- & & $16,028.22$ & -- & -- & & $16,028.22$ & -- & -- & \\
\hline \multirow[t]{2}{*}{01.} & Fixed intercept only & $-2 \mathrm{LL}$ & $16,146.00$ & 121.88 & $<.001$ & $* * *$ & $16,146.00$ & 121.88 & $<.001$ & $* * *$ & $16,146.00$ & 121.88 & $<.001$ & $* * *$ \\
\hline & & AIC & $16,150.00$ & 121.78 & $<.001$ & **** & $16,150.00$ & 121.78 & $<.001$ & $* * *$ & $16,150.00$ & 121.78 & $<.001$ & $* * *$ \\
\hline \multirow[t]{2}{*}{02.} & Random intercept only & $-2 \mathrm{LL}$ & $16,851.22$ & 705.22 & $<.001$ & $* * *$ & $16,851.22$ & 705.22 & $<.001$ & $* * *$ & $16,851.22$ & 705.22 & $<.001$ & $* * *$ \\
\hline & & AIC & $16,857.23$ & 707.23 & $<.001$ & $* * *$ & $16,857.23$ & 707.23 & $<.001$ & $* * *$ & $16,857.23$ & 707.23 & $<.001$ & $* * *$ \\
\hline \multirow[t]{2}{*}{03.} & Step 02 plus Gender & $-2 \mathrm{LL}$ & $16,446.25$ & -404.97 & $<.001$ & $* * *$ & $16,446.25$ & -404.97 & $<.001$ & $* * *$ & $16,446.25$ & -404.97 & $<.001$ & $* * *$ \\
\hline & & AIC & $16,452.26$ & -404.97 & $<.001$ & $* * *$ & $16,452.26$ & -404.97 & $<.001$ & $* * *$ & $16,452.26$ & -404.97 & $<.001$ & $* * *$ \\
\hline \multirow[t]{2}{*}{04.} & Step 03 plus Age & $-2 \mathrm{LL}$ & $15,184.69$ & $-1,261.56$ & $<.001$ & $* * *$ & $15,184.69$ & $-1,261.56$ & $<.001$ & $* * *$ & $15,184.69$ & $-1,261.56$ & $<.001$ & $* * *$ \\
\hline & & AIC & $15,190.70$ & $-1,261.56$ & $<.001$ & **** & $15,190.70$ & $-1,261.56$ & $<.001$ & $* * *$ & $15,190.70$ & $-1,261.56$ & $<.001$ & *** \\
\hline \multirow[t]{2}{*}{05.} & Step 04 plus Event & $-2 \mathrm{LL}$ & $15,189.90$ & 5.21 & $<.05$ & $*$ & $15,189.90$ & 5.21 & $<.05$ & $*$ & $15,189.90$ & 5.21 & $<.05$ & * \\
\hline & & AIC & $15,195.91$ & 5.21 & $<.05$ & $*$ & $15,195.91$ & 5.21 & $<.05$ & * & $15,195.91$ & 5.21 & $<.05$ & $*$ \\
\hline \multirow[t]{2}{*}{06.} & Step 05 plus Outcome & $-2 \mathrm{LL}$ & $15,194.35$ & 4.45 & $<.05$ & $*$ & $15,194.35$ & 4.45 & $<.05$ & * & $15,194.35$ & 4.45 & $<.05$ & $*$ \\
\hline & & AIC & $15,200.36$ & 4.45 & $<.05$ & $*$ & $15,200.36$ & 4.45 & $<.05$ & * & $15,200.36$ & 4.45 & $<.05$ & $*$ \\
\hline \multirow[t]{2}{*}{07.} & Step 06 plus Event $\times$ Outcome & $-2 \mathrm{LL}$ & $15,199.10$ & 4.75 & $<.05$ & * & $15,199.10$ & 4.75 & $<.05$ & * & $15,199.10$ & 4.75 & $<.05$ & * \\
\hline & & AIC & $15,205.10$ & 4.74 & $<.05$ & $*$ & $15,205.10$ & 4.74 & $<.05$ & * & $15,205.10$ & 4.74 & $<.05$ & * \\
\hline \multirow[t]{2}{*}{08.} & Step 07 plus Belief & $-2 \mathrm{LL}$ & $15,205.53$ & 6.43 & $<.05$ & $*$ & $15,201.84$ & 2.74 & $<.05$ & $*$ & $15,204.87$ & 5.77 & $<.05$ & $*$ \\
\hline & & AIC & $15,211.54$ & 6.44 & $<.05$ & $*$ & $15,207.85$ & 2.75 & $<.05$ & * & $15,210.88$ & 5.78 & $<.05$ & $*$ \\
\hline \multirow[t]{2}{*}{09.} & Step 08 plus Belief $\times$ Event & $-2 \mathrm{LL}$ & $15,209.61$ & 4.08 & $<.05$ & * & $15,202.44$ & .60 & $<.05$ & * & $15,209.04$ & 4.17 & $<.05$ & $*$ \\
\hline & & AIC & $15,215.61$ & 4.07 & $<.05$ & $*$ & $15,208.45$ & .60 & $<.05$ & $*$ & $15,215.05$ & 4.17 & $<.05$ & $*$ \\
\hline \multirow[t]{2}{*}{10.} & Step 09 plus Belief $\times$ Outcome & $-2 \mathrm{LL}$ & $15,230.46$ & 20.85 & $<.001$ & $* * *$ & $15,219.67$ & 17.23 & $<.001$ & $* * *$ & $15,235.66$ & 26.62 & $<.001$ & $* * *$ \\
\hline & & AIC & $15,236.46$ & 20.85 & $<.001$ & **** & $15,225.68$ & 17.23 & $<.001$ & $* * *$ & $15,241.69$ & 26.64 & $<.001$ & $* * *$ \\
\hline \multirow[t]{2}{*}{11} & Step 10 plus Belief $\times$ Event $\times$ Outcome & $-2 \mathrm{LL}$ & $15,234.58$ & 4.12 & $<.05$ & $*$ & $15,219.76$ & .09 & $<.05$ & $*$ & $15,240.86$ & 5.20 & $<.05$ & * \\
\hline & & AIC & $15,240.59$ & 4.13 & $<.05$ & $*$ & $15,225.77$ & .09 & $<.05$ & $*$ & $15,246.87$ & 5.18 & $<.05$ & * \\
\hline \multirow[t]{2}{*}{12.} & Step 11 plus NFC & $-2 \mathrm{LL}$ & $15,054.22$ & -180.36 & $<.001$ & $* * *$ & $15,039.57$ & -180.19 & $<.001$ & $* * *$ & $15,060.01$ & -180.85 & $<.001$ & $* * *$ \\
\hline & & AIC & $15,060.23$ & -180.36 & $<.001$ & $* * *$ & $15,045.58$ & -180.19 & $<.001$ & $* * *$ & $15,066.01$ & -180.86 & $<.001$ & $* * *$ \\
\hline \multirow[t]{2}{*}{13.} & Step 12 plus NFC $\times$ Event & $-2 \mathrm{LL}$ & $15,062.05$ & 7.83 & .001 & $* *$ & $15,047.97$ & 8.40 & .001 & $* *$ & $15,067.30$ & 7.29 & .001 & $* *$ \\
\hline & & AIC & $15,068.06$ & 7.83 & .001 & $* *$ & $15,053.98$ & 8.40 & .001 & $* *$ & $15,073.31$ & 7.30 & .001 & $* *$ \\
\hline \multirow[t]{2}{*}{14.} & Step 13 plus NFC $\times$ Outcome & $-2 \mathrm{LL}$ & $15,071.82$ & 9.77 & .001 & $* *$ & $15,054.73$ & 6.76 & .001 & $* *$ & $15,077.57$ & 10.27 & .001 & $* *$ \\
\hline & & AIC & $15,077.83$ & 9.77 & .001 & $* *$ & $15,060.74$ & 6.76 & .001 & $* *$ & $15,083.58$ & 10.27 & .001 & $* *$ \\
\hline \multirow[t]{2}{*}{15.} & Step 14 plus NFC $\times$ Event $\times$ Outcome & $-2 \mathrm{LL}$ & $15,073.30$ & 1.48 & $>.05$ & & $15,056.17$ & 1.44 & $>.05$ & & $15,079.05$ & 1.48 & $>.05$ & \\
\hline & & AIC & $15,079.30$ & 1.47 & $>.05$ & & $15,062.18$ & 1.44 & $>.05$ & & $15,085.05$ & 1.47 & $>.05$ & \\
\hline
\end{tabular}

${ }^{\dagger} \mathrm{PK}_{\mathrm{LOG}}$ denotes PK Beliefs subjected to natural logarithmic transformation; all models with first order auto-regressive (AR1) structures; model goodness-of-fit and complexity-corrected goodness-of-fit given by -2 Log Likelihood (-2LL) and Akaike's Information Criteria (AIC) respectively; $\triangle \chi^{2} d f=1$; PK Beliefs subjected to natural logarithmic transformation; figures to 2 decimal places; sig. change at the *p<.01 *** $p<.01$ and $* * * *<.001$ levels; term $\sim<.05 a$

$=$ approached significance (two-tailed; $n=3,777$ to 3,793 cases). 
Supplementary Table 2: GLMM Goodness-of-Fit \& -2LL Change Statistics for Conjunction Error Generation (Presence vs. Absence) by Paranormal Belief \& Model Types (continued)

\begin{tabular}{|c|c|c|c|c|c|c|c|c|c|c|c|c|c|c|}
\hline \multirow[b]{2}{*}{ Step } & \multirow[b]{2}{*}{ Predictor(s) Entered } & \multirow{2}{*}{$\begin{array}{c}\text { Fit } \\
\text { Index }\end{array}$} & \multicolumn{4}{|c|}{ ESP } & \multicolumn{4}{|c|}{$\mathrm{PK}$} & \multicolumn{4}{|c|}{ LAD } \\
\hline & & & $x^{2}$ & $\Delta \chi^{2}$ & $p$ & & $\chi^{2}$ & $\Delta \chi^{2}$ & $p$ & & $x^{2}$ & $\Delta \chi^{2}$ & $p$ & \\
\hline \multirow[t]{2}{*}{16.} & Step 15 plus FI & $-2 \mathrm{LL}$ & $15,079.37$ & 6.07 & $<.05$ & * & $15,062.02$ & 5.85 & $<.05$ & $*$ & $15,085.16$ & 6.11 & $<.05$ & * \\
\hline & & AIC & $15,085.39$ & 6.09 & $<.05$ & * & $15,068.02$ & 5.84 & $<.05$ & $*$ & $15,091.17$ & 6.12 & $<.05$ & * \\
\hline \multirow[t]{2}{*}{17.} & Step 16 plus FI $\times$ Event & $-2 \mathrm{LL}$ & $15,087.10$ & 7.73 & .001 & $* *$ & $15,068.59$ & 6.57 & $<.05$ & $*$ & $15,091.60$ & 6.44 & $<.05$ & * \\
\hline & & AIC & $15,093.11$ & 7.72 & .001 & $* *$ & $15,074.59$ & 6.57 & $<.05$ & $*$ & $15,097.60$ & 6.43 & $<.05$ & * \\
\hline \multirow[t]{2}{*}{18.} & Step 17 plus FI $\times$ Outcome & $-2 \mathrm{LL}$ & $15,090.26$ & 3.16 & $>.05$ & $a$ & $15,072.47$ & 3.88 & $<.05$ & * & $15,094.74$ & 3.14 & $>.05$ & $a$ \\
\hline & & AIC & $15,096.27$ & 3.16 & $>.05$ & $a$ & $15,078.48$ & 3.89 & $<.05$ & $*$ & $15,100.75$ & 3.15 & $>.05$ & $a$ \\
\hline \multirow[t]{2}{*}{19.} & Step 08 plus FI $\times$ Event $\times$ Outcome & $-2 \mathrm{LL}$ & $15,093.44$ & 3.18 & $>.05$ & $a$ & $15,076.13$ & 3.66 & $>.05$ & $a$ & $15,097.57$ & 2.83 & $>.05$ & \\
\hline & & AIC & $15,099.45$ & 3.18 & $>.05$ & $a$ & $15,082.14$ & 3.66 & $>.05$ & $a$ & $15,103.57$ & 2.82 & $>.05$ & \\
\hline
\end{tabular}

${ }^{\dagger} \mathrm{PK}_{\mathrm{LOG}}$ denotes PK Beliefs subjected to natural logarithmic transformation; all models with first order auto-regressive (AR1) structures; model goodness-of-fit and complexity-corrected goodness-of-fit given by -2 Log Likelihood $(-2 \mathrm{LL})$ and Akaike's Information Criteria (AIC) respectively; $\Delta \chi^{2} d f=1$; PK Beliefs subjected to natural logarithmic transformation; figures to 2 decimal places; sig. change at the * $p<.01 * * p<.01$ and **** $p<.001$ levels; term $\sim<.05 a$ $=$ approached significance (two-tailed; $n=3,777$ to 3,793 cases). 
Supplementary Table 3: GLMM Goodness-of-Fit \& -2LL Change Statistics for Conjunction Error Generation (Presence vs. Absence) by Paranormal Belief \& Intercept Types ${ }^{\dagger}$

\begin{tabular}{|c|c|c|c|c|c|c|c|c|c|c|c|c|c|c|}
\hline \multirow[t]{2}{*}{ Step } & \multirow[t]{2}{*}{ Intercept Type } & \multirow{2}{*}{$\begin{array}{c}\text { Fit } \\
\text { Index }\end{array}$} & \multicolumn{4}{|c|}{ ESP } & \multicolumn{4}{|c|}{ PK } & \multicolumn{4}{|c|}{ LAD } \\
\hline & & & $x^{2}$ & $\Delta \chi^{2}$ & $p$ & & $x^{2}$ & $\Delta \chi^{2}$ & $p$ & & $x^{2}$ & $\Delta \chi^{2}$ & $p$ & \\
\hline \multirow[t]{2}{*}{1} & Fixed intercept & $-2 \mathrm{LL}$ & $14,912.88$ & & & & $14,799.20$ & & & & $14,893.90$ & & & \\
\hline & & AIC & $14,916.88$ & & & & $14,803.20$ & & & & $14,897.90$ & & & \\
\hline \multirow[t]{2}{*}{2} & Random intercept & $-2 \mathrm{LL}$ & $15,512.51$ & 599.63 & $<.001$ & $* * *$ & $15,430.52$ & 631.32 & $<.001$ & $* * *$ & $15,514.33$ & 620.43 & $<.001$ & $* * *$ \\
\hline & & $\mathrm{AIC}$ & $15,518.52$ & 602.09 & $<.001$ & $* * *$ & $15,436.53$ & 633.33 & $<.001$ & $* * *$ & $15,520.34$ & 622.44 & $<.001$ & **** \\
\hline
\end{tabular}

${ }^{\dagger}$ PK Beliefs subjected to natural logarithmic transformation; all models with first order auto-regressive (AR1) covariance structures; model goodness-of-fit and complexity-corrected goodness-of-fit given by - 2 Log Likelihood (-2LL) and Akaike's Information Criteria (AIC) respectively; $\triangle \chi^{2} d f=1$; figures to 2 decimal places; smaller figures indicate better model fit. Significant. change at the $* p<.01 * * p<.01$ and $* * * p<.001$ levels (two-tailed; $n=3,777$ to 3,793 cases). 


\section{Supplementary Text}

\section{Follow-up Analyses Incorporating Paranormal Belief x Thinking Style Interactions}

Following reviewer comments, follow-up GLMMs were performed to further test the impact individual differences in thinking style had on believers' proneness to (confirmatory) conjunction errors. First, raw NFC and FI ratings were subjected to median split analysis and dichotomized into low verses high NFC ( $49.6 \%$ versus $50.4 \%$ respectively; median $=4.32$ ) and low verses high FI (49.8\% versus 50.2\% respectively; median=4.91). Then paranormal belief, dichotomized NFC and FI measures, outcome type and relevant interaction terms were entered as into each of three GLMMs - one each for ESP, (log transformed) PK and LAD beliefs - with, as before, respondent gender and age serving as potential covariates. Because event type had no significant main or interaction effects on CE rates in primary analyses, this variable was dropped. All other GLMM characteristics (e.g., use of grand mean centring inclusion of the random intercept term and AR1 covariance structure) were retained.

\section{Classification Accuracy}

As Supplementary Table 4 shows, classification accuracy rates for the three follow-up GLMMs differed only slightly from those reported in the main text. This time, the percentage of conjunction errors correctly classified by ESP based and PK based models fell by $0.1 \%$ whereas for the LAD based model it increased by $0.6 \%$. Likewise, the percentage of nonerrors correctly classified in the ESP, PK and LAD based models fell by $0.1 \%, 0.4 \%$ and $1.3 \%$ respectively. Finally, the classification accuracy for all responses dropped by $0.1 \%$, $0.3 \%$ and $0.6 \%$ respectively. In sum, inclusion of relevant belief $\times$ thinking style interactions (plus removal of the event type variable) had only minimal impact on the predictive accuracy of follow-up models.

*** Supplementary Table 4 here $* * *$ 


\section{Predictors of Conjunction Error Generation}

As Supplementary Table 5 shows, predictor coefficients for the three follow-up GLMMs were, for the most part, parallel to those reported in primary analyses. Noteworthy differences were as follows.

First, the effect of NFC ratings dropped to just below statistical significance in the followup PK model ( $p=.060)$. These remained significant in both ESP and LAD models.

Second, NFC $\times$ outcome interactions switched from being a near-significant positive predictor to a (fully) significant but negative predictor of CE rates. This was the case for all three belief-based models. Relevant $\exp (b)$ coefficients indicate that with all other predictors averaged, the shift from low to high NFC (coded -1 and +1 respectively) combined with a shift from disconfirmatory to a confirmatory outcome raised the odds of CE generation by around .55. At first glance it seems individuals with a low NFC were $1 / .55$ or 1.82 times more likely to commit confirmatory CEs than those with high NFC. This is consistent with main analyses, with the change in sign of beta weights reflective of how the low verses high NFC dichotomy was coded (see Supplementary Figure 1). However, post hoc simple effects analyses - with $\alpha$ adjusted to .0125 - failed to confirm these differences (all $p$ 's $>.023 ; n s$ ).

$$
\text { *** Supplementary Figure } 1 \text { here *** }
$$

Third, whilst no significant belief $\times$ NFC effects emerged in relation to ESP and PK, a near-significant LAD belief $\times$ NFC effect was found $(p=.062)$. Associated $\exp (b)$ coefficients suggest that with all other predictors averaged, a shift from low to high NFC combined with a unit increase in LAD beliefs (marginally) increased the odds of CE generation by a ratio of .76. In other words, as level of LAD belief increased by one unit, believers high in NFC were 1/.76 or 1.32 times less likely to make a CE than were LAD believers low in NFC. This time, post hoc tests - again with $\alpha$ adjusted to .0125 - confirmed that stronger LAD believers with low NFC were more likely to make CEs than were stronger LAD believers with high NFC, 
$b=.37 ; t=3.67 ; p<.001 ; \exp (b)=1.41 ; C_{95}[1.17,1.69]$. This was further qualifies by a significant LAD belief $\times$ outcome type interaction in that stronger LAD believers with low NFC were more likely to make confirmatory CEs than corresponding LAD sceptics with high NFC, $b=-.28 ; t=-3.88 ; p<.001 ; \exp (b)=.75 ; C I_{95}[.65, .78]$. For LAD believers with low NFC, comparable effects for CEs generally $(p=.027 ; n s)$ and for confirmatory CEs in particular $(p=.030 ; n s)$ were not significant at the adjusted $\alpha$ level. To illustrate these effects, LAD beliefs were split low verses high categories (50.6\% versus $49.4 \%$ respectively; median=4.02) and combined with low verses high NFC to make four LAD x NFC classifications. CE rates for these four classifications across confirmatory verses disconfirmatory outcome types are presented in Supplementary Figure 2. From this it would seem LAD sceptics who prefer to adopt a more rational-analytic (System 2) thinking style were less prone to a confirmatory conjunction fallacy than all other groups.

*** Supplementary Figure 2 here ***

Finally, minor variation was also found in the main effect of FI which was now nonsignificant in the PK as well as ESP and LAD models. All other main and interaction effects involving FI were non-significant with no other changes (relative to main analyses) emerging.

In sum, follow-up analyses suggest the impact stronger paranormal belief had on $\mathrm{CE}$ generation depended, to some extent, on the strength of respondents' preference for rationalanalytic but not intuitive-experiential thinking. Surprisingly, this was only true for LAD believers; those who prefer to shun rational-analytic (System 2) thinking made more confirmatory CEs than LAD believers' more inclined to employ logical reasoning. In other words, having a higher need for cognition results in fewer confirmatory CEs for those relatively sceptical of life after death but not for individuals endorsing the veracity of afterlife 
claims. But as previously suggested, this single effect is likely to be a statistical artefact particularly when considered in the context of other cross-belief type trends. 
Supplementary Table 4: Percentage of Conjunction Errors, Non-Errors \& All Responses Correctly Predicted by Paranormal Belief \& Intercept Types: Follow-Up Analyses $^{\dagger}$

\begin{tabular}{|c|c|c|c|c|}
\hline Response & Intercept & ESP & $\mathrm{PK}$ & LAD \\
\hline Type & Type & $(\%)$ & $(\%)$ & $(\%)$ \\
\hline \multirow[t]{2}{*}{ Errors } & Fixed & 18.4 & 20.7 & 22.6 \\
\hline & Random & 58.1 & 57.6 & 58.9 \\
\hline \multirow{2}{*}{ Non-errors } & Fixed & 88.5 & 87.1 & 85.9 \\
\hline & Random & 79.9 & 80.4 & 79.7 \\
\hline \multirow[t]{2}{*}{ All } & Fixed & 58.8 & 59.1 & 59.1 \\
\hline & Random & 70.7 & 70.8 & 70.9 \\
\hline
\end{tabular}

${ }^{\dagger}$ PK Beliefs subjected to natural logarithmic transformation; models with first order auto-regressive (AR1) covariance structure; thinking styles dichotomised into low verses high NFC (49.6\% versus 50.4\%) and low verses high FI (49.8\% versus 50.2) via media split analysis; figures to one decimal place ( $n=3,362$ to 3,378 cases). 
Supplementary Table 5: Predictors of Conjunction Error Generation (Presence vs. Absence) by Paranormal Belief Type: Follow-Up Analyses $^{\dagger}$

\begin{tabular}{|c|c|c|c|c|c|c|c|c|c|c|c|c|c|c|c|c|c|c|c|c|c|}
\hline \multirow[b]{3}{*}{ Predictor } & \multicolumn{7}{|c|}{ ESP } & \multicolumn{7}{|c|}{ PK } & \multicolumn{7}{|c|}{ LAD } \\
\hline & \multirow[b]{2}{*}{$b$} & \multirow[b]{2}{*}{$t$} & \multirow[b]{2}{*}{$P$} & & \multirow[b]{2}{*}{$\exp (b)$} & \multicolumn{2}{|c|}{$95 \% C I$} & \multirow[b]{2}{*}{$b$} & \multirow[b]{2}{*}{$t$} & \multirow[b]{2}{*}{$p$} & & \multirow[b]{2}{*}{$\exp (b)$} & \multicolumn{2}{|c|}{$95 \% C I$} & \multirow[b]{2}{*}{$b$} & \multirow[b]{2}{*}{$t$} & \multirow[b]{2}{*}{$p$} & & \multirow[b]{2}{*}{$\exp (b)$} & \multicolumn{2}{|c|}{$95 \% C I$} \\
\hline & & & & & & Lwr & Upr & & & & & & Lwr & Upr & & & & & & Lwr & Upr \\
\hline Random Intercept & .86 & .42 & .674 & & 2.37 & .04 & 131.26 & .93 & .45 & .654 & & 2.53 & .04 & 146.65 & .94 & .45 & .651 & & 2.56 & .04 & 149.21 \\
\hline Gender & -.04 & -.26 & .796 & & .96 & .71 & 1.30 & -.09 & -.59 & .559 & & .91 & .67 & 1.24 & -.03 & -.19 & .848 & & .97 & .72 & 1.32 \\
\hline Age & .04 & .68 & .497 & & 1.04 & .93 & 1.18 & .04 & .64 & .523 & & 1.04 & .92 & 1.17 & .04 & .67 & .503 & & 1.04 & .92 & 1.18 \\
\hline Outcome (O) & .29 & 2.06 & .040 & $*$ & 1.33 & 1.01 & 1.75 & .20 & 1.48 & .138 & & 1.22 & .94 & 1.60 & .23 & 1.67 & .096 & & 1.25 & .96 & 1.64 \\
\hline Belief (B) & .45 & 4.29 & $<.001$ & $* * *$ & 1.57 & 1.28 & 1.94 & 1.96 & 3.32 & .001 & $* *$ & 7.12 & 2.23 & 22.74 & .34 & 3.73 & $<.001$ & $* * *$ & 1.40 & 1.17 & 1.69 \\
\hline $\mathrm{B} \times \mathrm{O}$ & -.03 & -3.50 & $<.001$ & $* * *$ & .73 & .62 & .87 & -1.52 & -3.08 & .002 & $* *$ & .22 & .08 & .58 & -.28 & -3.77 & $<.001$ & $* * *$ & .76 & .65 & .87 \\
\hline NFC & .54 & 2.13 & .033 & $*$ & 1.71 & 1.04 & 2.81 & .48 & 1.88 & .060 & $a$ & 1.61 & .98 & 2.64 & .57 & 2.21 & .027 & $*$ & 1.78 & 1.07 & 2.95 \\
\hline $\mathrm{NFC} \times \mathrm{O}$ & -.64 & -3.04 & .002 & $* *$ & .53 & .35 & .80 & -.57 & -2.74 & .006 & $* *$ & .57 & .38 & .85 & -.60 & -2.82 & .005 & $* *$ & .55 & .36 & .83 \\
\hline $\mathrm{NFC} \times \mathrm{B}$ & -.21 & -1.32 & .188 & & .81 & .59 & 1.11 & -1.11 & -1.25 & .213 & & .33 & .09 & 1.89 & -.28 & -1.87 & .062 & $a$ & .76 & .57 & 1.01 \\
\hline $\mathrm{NFC} \times \mathrm{B} \times \mathrm{O}$ & .00 & .01 & .992 & & 1.00 & .77 & 1.31 & -.06 & -.08 & .940 & & .95 & .22 & 4.01 & .06 & .49 & .628 & & 1.06 & .83 & 1.35 \\
\hline FI & .03 & .13 & .896 & & 1.03 & .63 & 1.69 & -.04 & -.13 & .894 & & .97 & .58 & 1.61 & -.03 & -.11 & .916 & & .97 & .59 & 1.60 \\
\hline $\mathrm{FI} \times \mathrm{O}$ & -.13 & -.60 & .3550 & & .88 & .58 & 1.34 & -.06 & -.26 & .798 & & .95 & .62 & 1.45 & -.07 & -.32 & .749 & & .94 & .62 & 1.41 \\
\hline $\mathrm{FI} \times \mathrm{B}$ & -.13 & -.80 & .424 & & .88 & .64 & 1.21 & -.11 & -.12 & .909 & & .90 & .14 & 5.94 & .00 & .03 & .977 & & 1.00 & .75 & 1.36 \\
\hline $\mathrm{FI} \times \mathrm{B} \times \mathrm{O}$ & .23 & 1.61 & .107 & & 1.25 & .95 & 1.65 & 1.01 & 1.26 & .207 & & 2.75 & .57 & 13.27 & .20 & 1.55 & .121 & & 1.22 & .95 & 1.57 \\
\hline NFC $x$ FI & -.30 & -.86 & .392 & & .74 & .37 & 1.48 & -.30 & -.80 & .423 & & .75 & .36 & 1.53 & -.36 & -1.01 & .314 & & .70 & .34 & 1.41 \\
\hline NFC $x$ FI x O & .38 & 1.27 & .205 & & 1.46 & .81 & 2.61 & .34 & 1.13 & .261 & & 1.41 & .78 & 2.54 & .34 & 1.14 & .253 & & 1.41 & .78 & 2.54 \\
\hline $\mathrm{NFC} \times \mathrm{FI} \times \mathrm{B}$ & -.06 & -.27 & .791 & & .94 & .58 & 1.51 & -.75 & -.56 & .578 & & .47 & .03 & 6.61 & .11 & .47 & .638 & & 1.11 & .72 & 1.73 \\
\hline $\mathrm{NFC} \times \mathrm{FI} \times \mathrm{B} \times \mathrm{O}$ & .04 & .21 & .835 & & 1.04 & .70 & 1.56 & .10 & .09 & .927 & & 1.11 & .12 & 9.97 & -13 & -.69 & .490 & & .88 & .61 & 1.27 \\
\hline AR1 Diagonal ${ }^{\ddagger}$ & .92 & 38.91 & $<.001$ & $* * *$ & -- & .88 & .97 & .92 & 38.82 & $<.001$ & $* * *$ & -- & .88 & .97 & .92 & 38.89 & $<.001$ & $* * *$ & -- & .88 & .97 \\
\hline AR1 Rho & .05 & 2.54 & .011 & $*$ & -- & .01 & .09 & .05 & 2.50 & .012 & $*$ & -- & .01 & .09 & .05 & 2.61 & .009 & $*$ & -- & .01 & .09 \\
\hline
\end{tabular}

${ }^{\dagger}$ Figures for model with AR1 structure and random intercept; PK Beliefs subjected to natural logarithmic transformation; all continuous measures subjected to grand mean centring; models with first order autoregressive (AR1) covariance structure; thinking styles dichotomised into low verses high NFC (49.6\% versus 50.4\%) and low verses high FI (49.8\% versus 50.2) via media split analysis; higher scores reflect more $\mathrm{NFC}$, more FI and female gender; inferential statistic for ARl Rho (intraclass correlation coefficient) and ARI Diagonal (estimated variance) is $Z$ rather than $t$. Significant effects at the * $p<.05 * * p<.01$ and $* * * p<.00$ level; $a=$ approaches significance (two-tailed; $n=3,362$ to 3,378 cases) 


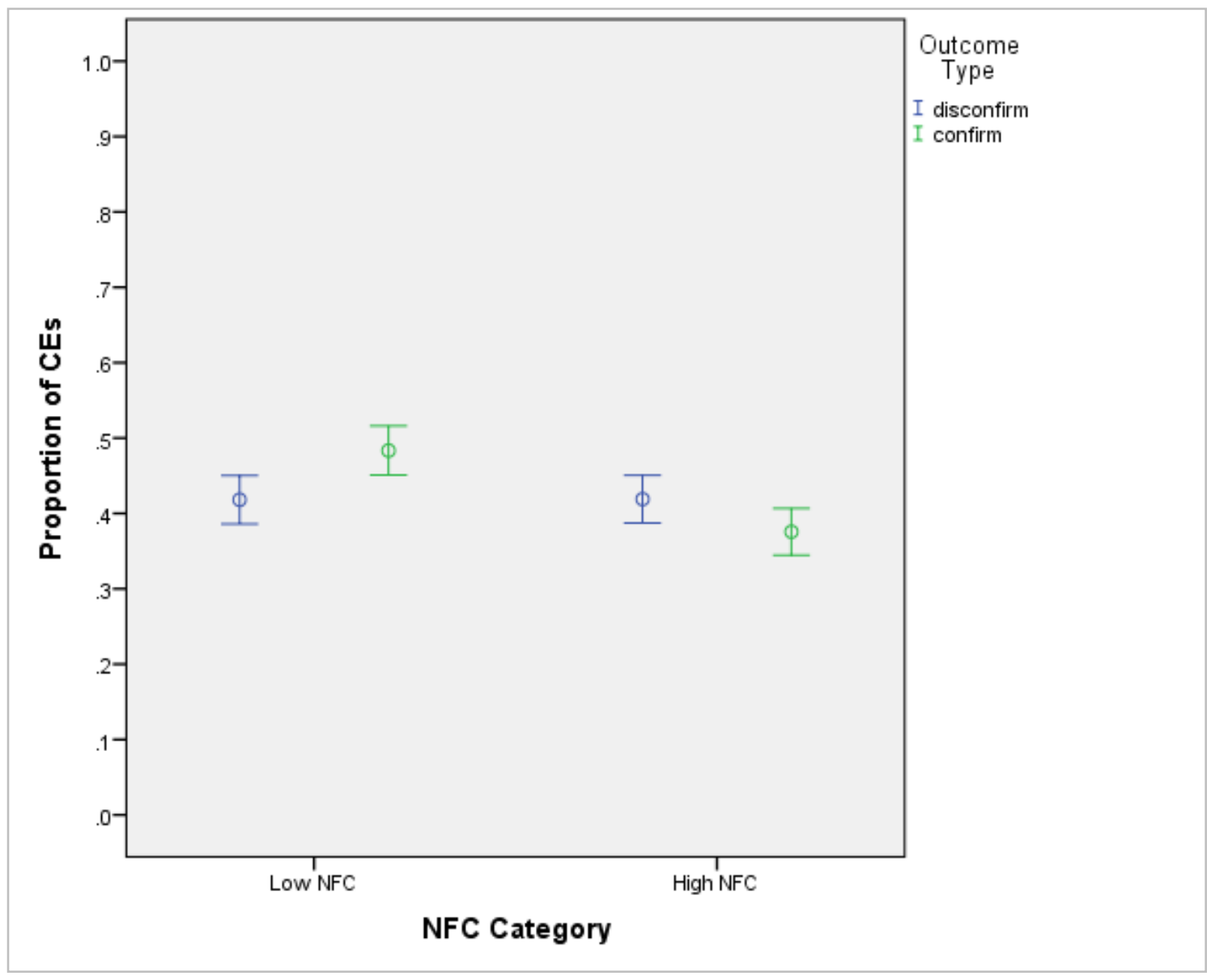

Supplementary Figure 1: Conjunction Error Rate across Low versus High NFC by Outcome Type (with 95\% Confidence Intervals) 


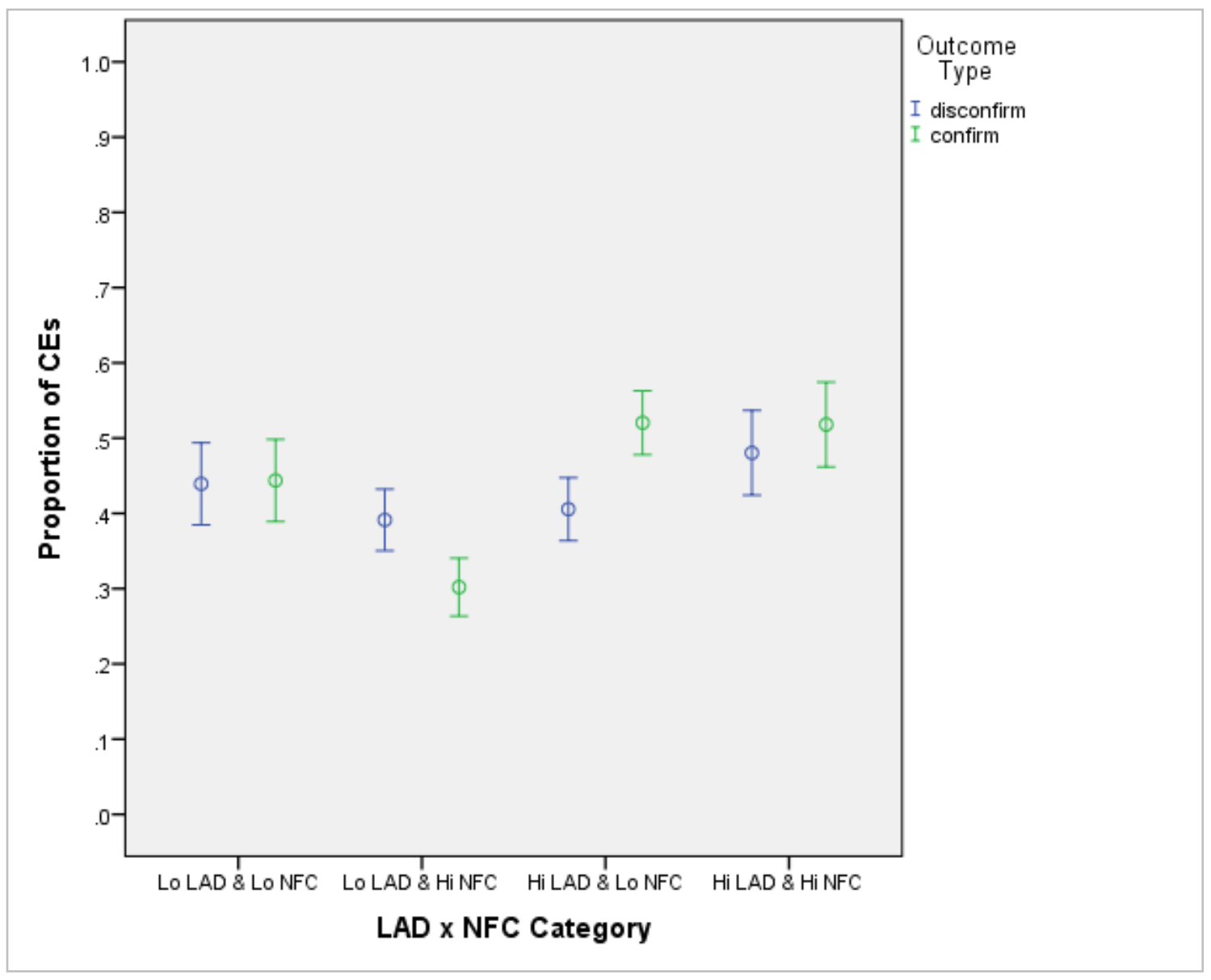

Supplementary Figure 2: Conjunction Error Rate across Four LAD × NFC Categories by Outcome Type (with 95\% Confidence Intervals) 